\title{
Influence of the Upstream Terrain on the Formation of a Cold Frontal Snowband in Northeast China
}

\author{
$\mathrm{Na} \mathrm{Li}^{1} \cdot$ Baofeng Jiao ${ }^{1} \cdot$ Lingkun Ran $^{1} \cdot$ Zongting Gao ${ }^{2}$. Shouting Gao ${ }^{1,3}$ \\ Received: 21 July 2020 / Revised: 15 April 2021 / Accepted: 15 April 2021 / Published online: 17 August 2021 \\ (C) The Author(s) 2021
}

\begin{abstract}
We investigated the influence of upstream terrain on the formation of a cold frontal snowband in Northeast China. We conducted numerical sensitivity experiments that gradually removed the upstream terrain and compared the results with a control experiment. Our results indicate a clear negative effect of upstream terrain on the formation of snowbands, especially over large-scale terrain. By thoroughly examining the ingredients necessary for snowfall (instability, lifting and moisture), we found that the release of mid-level conditional instability, followed by the release of low-level or near surface instabilities (inertial instability, conditional instability or conditional symmetrical instability), contributed to formation of the snowband in both experiments. The lifting required for the release of these instabilities was mainly a result of frontogenetic forcing and upper gravity waves. However, the snowband in the control experiment developed later and was weaker than that in the experiment without upstream terrain. Two factors contributed to this negative topographic effect: (1) the mountain gravity waves over the upstream terrain, which perturbed the frontogenetic circulation by rapidly changing the vertical motion and therefore did not favor the release of instabilities in the absence of persistent ascending motion; and (2) the decrease in the supply of moisture as a result of blocking of the upstream terrain, which changed both the moisture and instability structures leeward of the mountains. A conceptual model is presented that shows the effects of the instabilities and lifting on the development of cold frontal snowbands in downstream mountains.
\end{abstract}

Keywords Snowbands $\cdot$ Leeward precipitation $\cdot$ Instability $\cdot$ Cold fronts

\section{Introduction}

Northeast China is located in the mid- and high latitudes of East Asia and includes the provinces of northeastern Inner Mongolia, Heilongjiang, Jilin and Liaoning (Fig. 1). Snowfall often occurs in this region during winter and early spring and can cause damage to agricultural crops,

Responsible Editor: Wei Wang.

Lingkun Ran

rlk@mail.iap.ac.cn

1 Institute of Atmospheric Physics, Chinese Academy of Sciences, Beijing 100029, China

2 Institute of Jilin Meteorological Research, Jilin Meteorological Service, Changchun 130062, China

3 Guizhou Key Lab of Mountounious Climate \& Resources, Guizhou Institute of Mountain Environment and Climate, Guizhou Meteorological Bureau, Guiyang, China animal husbandry practices and fisheries, in addition to affecting both air and surface traffic, resulting in large socioeconomic losses (Burnett et al. 2003; Wang et al. 2011a and b).

Many studies have been carried out with the aim of understanding the dynamics and thermodynamics of snowstorms and how these may affect weather forecasting. Niziol et al. (1995) reviewed the characteristics and development of mesoscale snowbands induced by lake effects in the eastern USA and designed several operational techniques to forecast lakeeffect snow events. A series of papers by Novak et al. (2004, $2006,2008,2009,2010)$ systematically studied the observational features, dynamic mechanisms and forecasts of snowbands at the comma heads of extratropical cyclones in the northeastern USA. Milrad et al. (2011) documented a type of snow squall, referred to as a snow burst, and distinguished it from lake-effect snow squalls or snowbands in extratropical cyclones. The dynamics and thermodynamics of these events have been reported by Pettegrew et al. (2009), Schumacher et al. (2010) and Milrad et al. (2014). 
Fig. 1 Observed liquidequivalent precipitation (colored dots; units: $\mathrm{mm}$ ) over $24 \mathrm{~h}$ ending at 0000 UTC on 27 January 2017 and the terrain height (shading; units: $m$ ) in Northeast China. The red box indicates the region in which the snowband formed. The blue dashed line indicates the edge of the upstream terrain for the following terrain sensitivity experiments

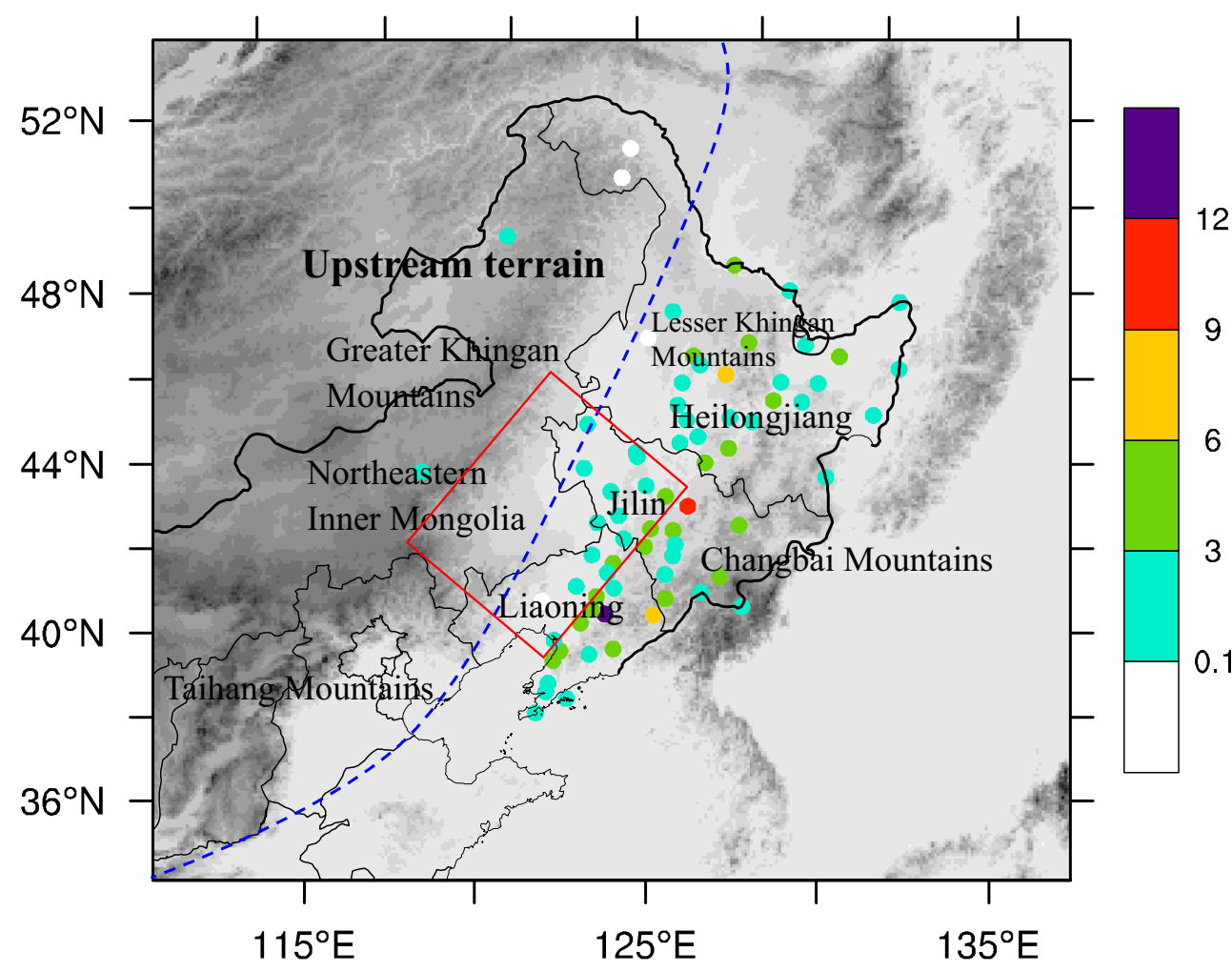

Similar studies have been carried out in Northeast China as a result of the high frequency of snow storms in this region. For instance, Sun et al. (2009) explored the mechanisms responsible for the extreme snowstorms that occurred in Northeast China on 3-5 March 2007 and showed that the anomalous atmospheric circulation and associated accumulation of moisture provided the basic energy source for this large snowfall event. Wang et al. (2011a and b) analyzed an exceptionally heavy snowfall event that occurred in Northeast China on 12-13 April 2010. They showed that the heavy snowfall could be attributed to the Siberian high, which intensified and shifted southeastward before the snowfall event, resulting in the strong convergence of water vapor and vertical motion over the eastern part of Northeast China. Most of these earlier studies have concentrated on the largescale environmental conditions during heavy snowfall events (e.g., Sun and Wang 2013). By contrast, detailed studies on the inner structures, dynamic mechanisms and shortterm forecasts of snowstorms in Northeast China are limited in number.

Northeast China has a complex terrain and there are significant orographic effects on precipitation in this region. The Greater Khingan Mountains lie to the west, the Changbai Mountains to the east and the central region consists of large areas of plains and rivers (Fig. 1). Statistical climate research by Dong et al. (2010) indicated that the areas southeast of the Changbai Mountains, south of the Liaodong Peninsula and northwest of the Greater Khingan Mountains experience high frequencies of heavy snowfall. All these areas are located on the windward side of the mountains, although precipitation also occurs leeward of the high terrain. The intensification of precipitation as a result of the orographic effects of windward mountains are relatively well known, but their influence on precipitation to the leeward side is not yet clear.

Kirshbaum and Schultz (2018) referred to the precipitation bands that develop over the leeward side of mountains as "downwind bands" and discussed the conditions for their formation. Compared with the well-studied upwind bands on the windward side of mountains (e.g., Kirshbaum and Durran 2005; Cosma et al. 2002), the dynamic mechanisms driving the downwind bands are subject to ongoing research and there are difficulties in forecasting these bands. A possible reason

Table. 1 Physical schemes used in the numerical experiments

\begin{tabular}{ll}
\hline Physical scheme & All experiments \\
\hline Land surface model & PX LSM \\
Planetary boundary layer & ACM2 \\
Microphysics & Morrison \\
& double-moment scheme \\
$\begin{array}{l}\text { Longwave and shortwave } \\
\text { radiation scheme }\end{array}$ & CAM \\
\hline
\end{tabular}




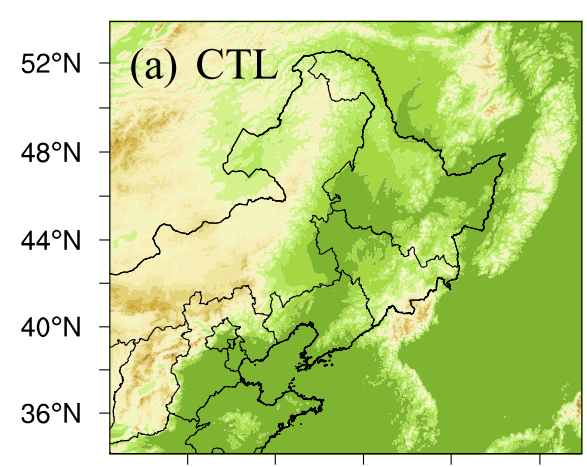

$115^{\circ} \mathrm{E} 120^{\circ} \mathrm{E} 125^{\circ} \mathrm{E} 130^{\circ} \mathrm{E} 135^{\circ} \mathrm{E}$

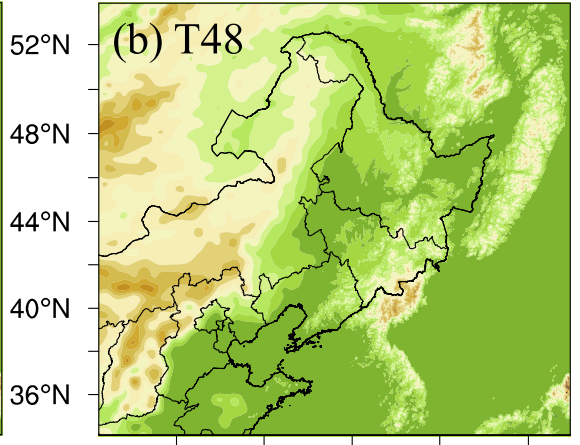

$115^{\circ} \mathrm{E} 120^{\circ} \mathrm{E} 125^{\circ} \mathrm{E} 130^{\circ} \mathrm{E} 135^{\circ} \mathrm{E}$

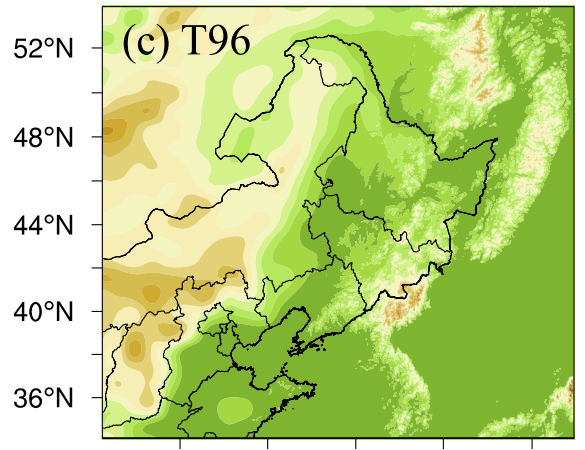

$115^{\circ} \mathrm{E} 120^{\circ} \mathrm{E} 125^{\circ} \mathrm{E} 130^{\circ} \mathrm{E} 135^{\circ} \mathrm{E}$

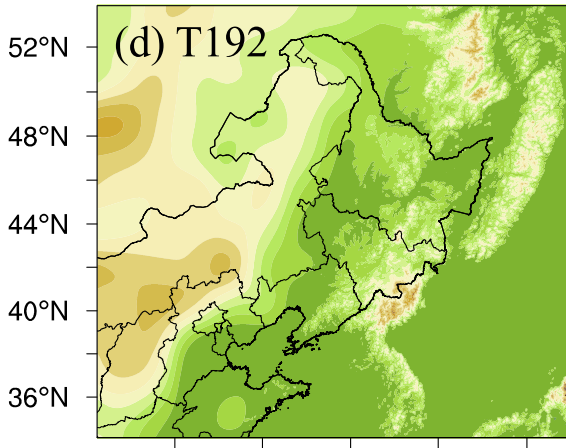

$115^{\circ} \mathrm{E} 120^{\circ} \mathrm{E} 125^{\circ} \mathrm{E} 130^{\circ} \mathrm{E} 135^{\circ} \mathrm{E}$

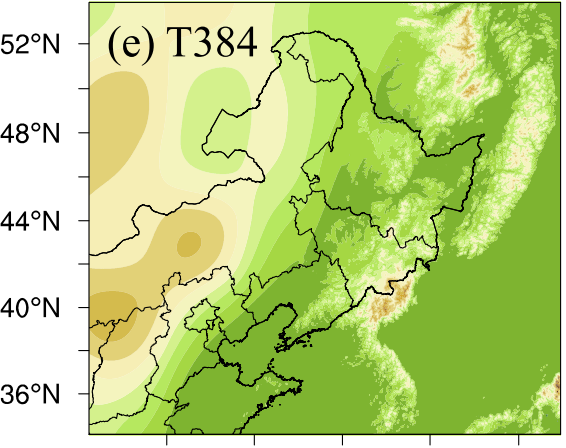

$115^{\circ} \mathrm{E} 120^{\circ} \mathrm{E} 125^{\circ} \mathrm{E} 130^{\circ} \mathrm{E} 135^{\circ} \mathrm{E}$

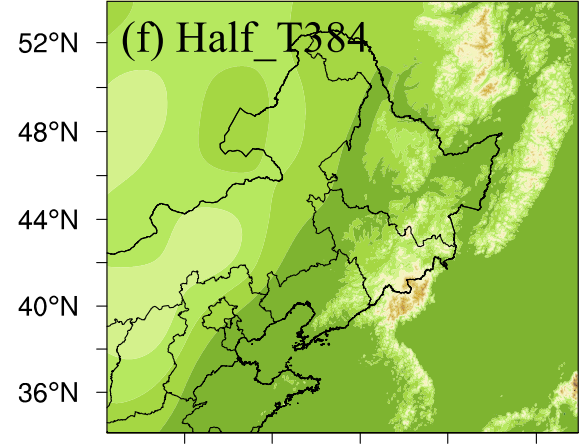

$115^{\circ} \mathrm{E} 120^{\circ} \mathrm{E} 125^{\circ} \mathrm{E} 130^{\circ} \mathrm{E} 135^{\circ} \mathrm{E}$

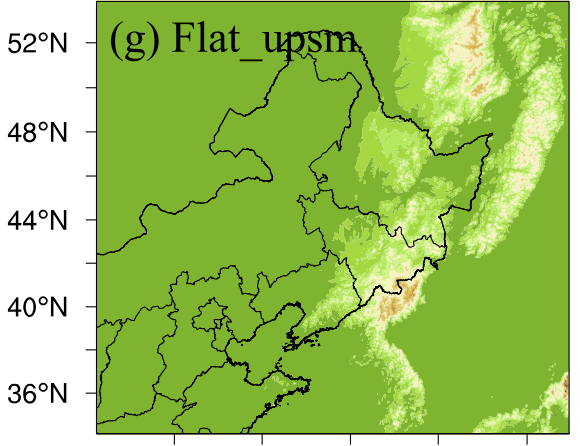

$115^{\circ} \mathrm{E} 120^{\circ} \mathrm{E} 125^{\circ} \mathrm{E} 130^{\circ} \mathrm{E} 135^{\circ} \mathrm{E}$

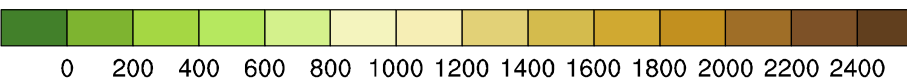

Fig. 2 Model terrain heights for the numerical experiments: (a) CTL; (b) T48; (c) T96; (d) T192; (e) T394; (f) Half_T384; and (g) Flat_upsm (units: m)

Table. 2 Summary of the sensitivity experiments. The upstream terrain indicates the terrain to the left of the blue line in Fig. 1

\begin{tabular}{lll}
\hline Experiment & Terrain & Snowband formation time (UTC) \\
\hline CTL & Full & 0400 \\
T48 & $>48 \mathrm{~km}$ & 0400 \\
T96 & $>96 \mathrm{~km}$ & 0400 \\
T192 & $>192 \mathrm{~km}$ & 0400 \\
T384 & $>384 \mathrm{~km}$ & 0300 \\
Half_T384 & Half of the T384 upstream terrain & 0200 \\
Flat_upsm & Upstream terrain $=200 \mathrm{~m}$ & 0000 \\
\hline
\end{tabular}


for this difficulty is the complex and rigorous dynamic and thermodynamic conditions required for their formation.

Using idealized sensitivity experiments, Kirshbaum and Schultz (2018) showed that the elongated downwind bands require a multilayer upstream static stability profile to form, with a conditionally unstable mid-level layer overlying a completely stable surface-based layer. Barrett et al. (2015) found that the amount and location of precipitation in
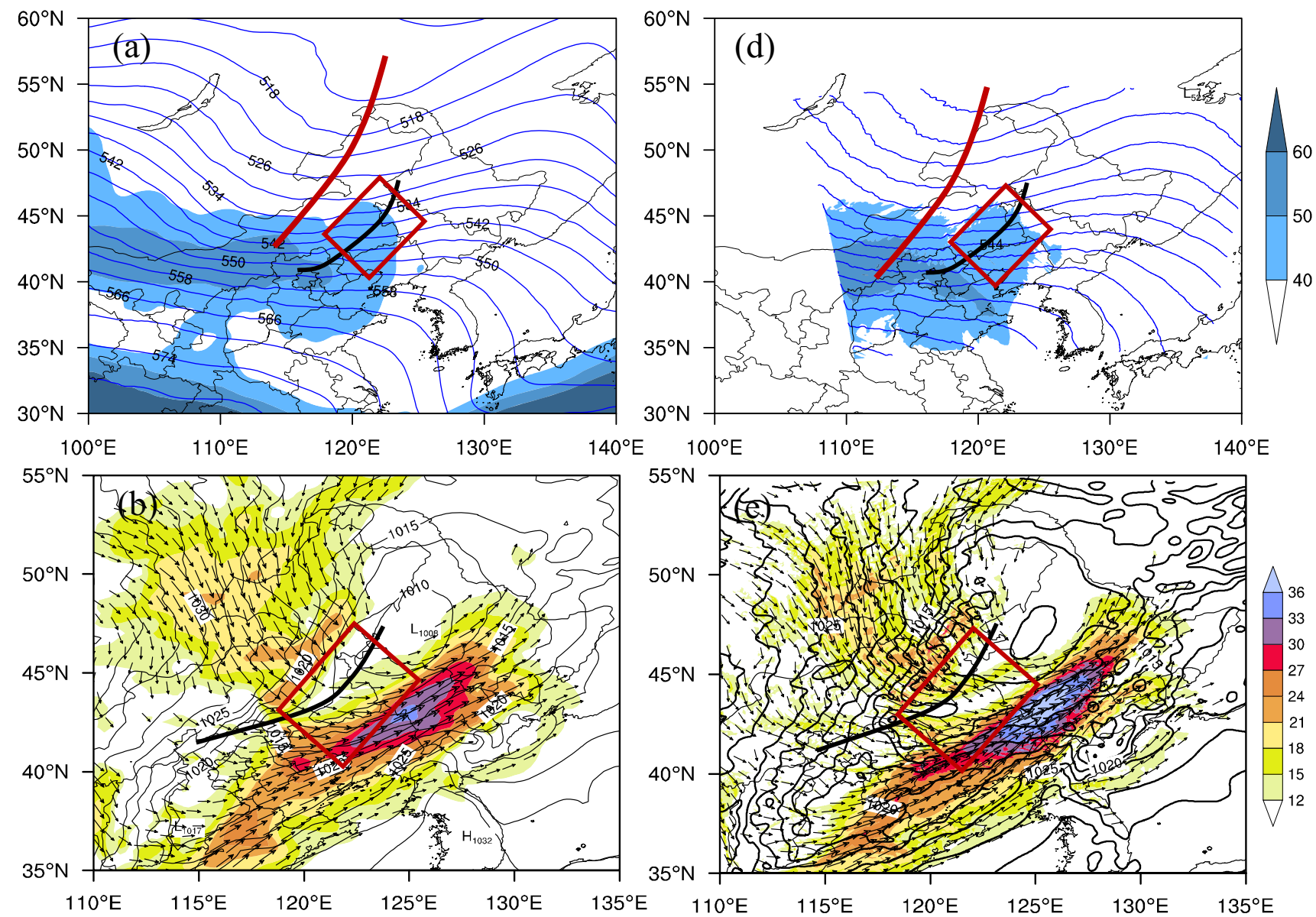

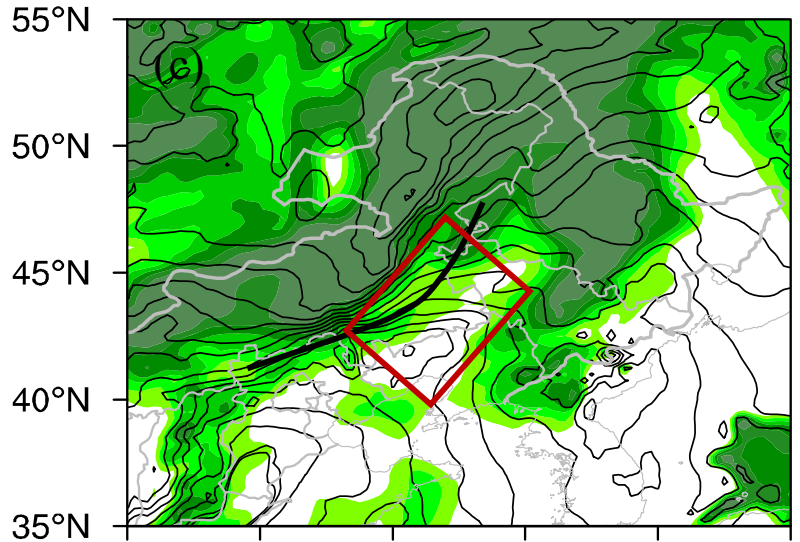

$110^{\circ} \mathrm{E} \quad 115^{\circ} \mathrm{E} \quad 120^{\circ} \mathrm{E} \quad 125^{\circ} \mathrm{E} \quad 130^{\circ} \mathrm{E} \quad 135^{\circ} \mathrm{E}$

Fig. 3 (a, b) Geopotential height (blue contours; units: $10 \mathrm{gpm}$ ) at $500 \mathrm{hPa}$ and wind speeds $>40 \mathrm{~m} \mathrm{~s}^{-1}$ at $200 \mathrm{hPa}$ (blue shading; units: $\mathrm{m}$ $\mathrm{s}^{-1}$ ). (c, d) Sea-level pressure (black contours; units: hPa; intervals: $2.5 \mathrm{hPa}$ ) and wind vectors with wind speeds $>12 \mathrm{~m} \mathrm{~s}^{-1}$ at $850 \mathrm{hPa}$ (colored shading). (e, f) Saturated equivalent potential temperature (black contours; units: $\mathrm{K}$; intervals: $2 \mathrm{~K}$ ) and relative humidity (shading; units:

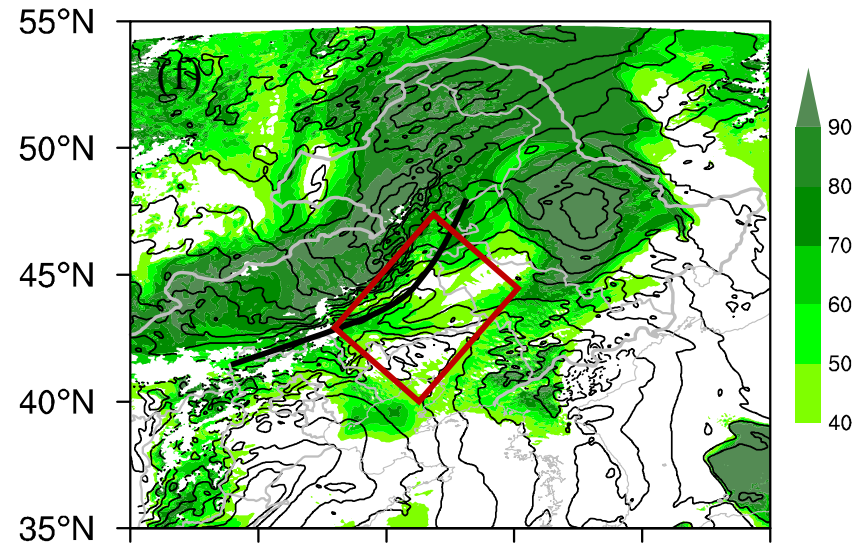

$110^{\circ} \mathrm{E} \quad 115^{\circ} \mathrm{E} \quad 120^{\circ} \mathrm{E} \quad 125^{\circ} \mathrm{E} \quad 130^{\circ} \mathrm{E} \quad 135^{\circ} \mathrm{E}$

$\%)$ at $850 \mathrm{hPa}$ at $0000 \mathrm{UTC}$ on 26 January 2017. The maps in the lefthand column are from the ECMWF analyses and those in the right-hand column are from the CTL experiment. The solid black lines are cold fronts. The solid red line in parts (a) and (d) is the $500 \mathrm{hPa}$ trough. The red boxes indicate the region in which the snowband formed 
stationary convective bands along a ridge of the Yorkshire Dales downwind of the Lake District in northern England was sensitive to small perturbations in the large-scale conditions. They showed that two processes contributed to the formation of rainbands: (1) leeside convergence resulting from flow around the Lake District; and (2) thermally forced convergence resulting from elevated heating above the Lake District. Low wind speeds on the upstream side of the mountain were necessary to develop convergence, but only three of 21 ensemble predictions captured these low wind speeds.

Inertial instability or dry symmetrical instability is also related to downwind bands. The decrease in wind speed in the wake of an obstacle creates strong horizontal shear and, as a result, couplets of vorticity and potential vorticity, referred to as potential vorticity banners, often form downstream of the mountains (e.g., Rotunno and Ferretti 2003; Jiang et al. 2003). Negative potential vorticity banners are inertially or symmetrically unstable and may therefore contribute to the development of downwind bands, including frontogenetic forcing and moist instabilities. It is still unclear whether potential vorticity banners are associated with precipitation. Jiang et al. (2003) reported that these banners had corresponding clouds, whereas Schär et al. (2003) suggested that these banners were primarily deformational and were
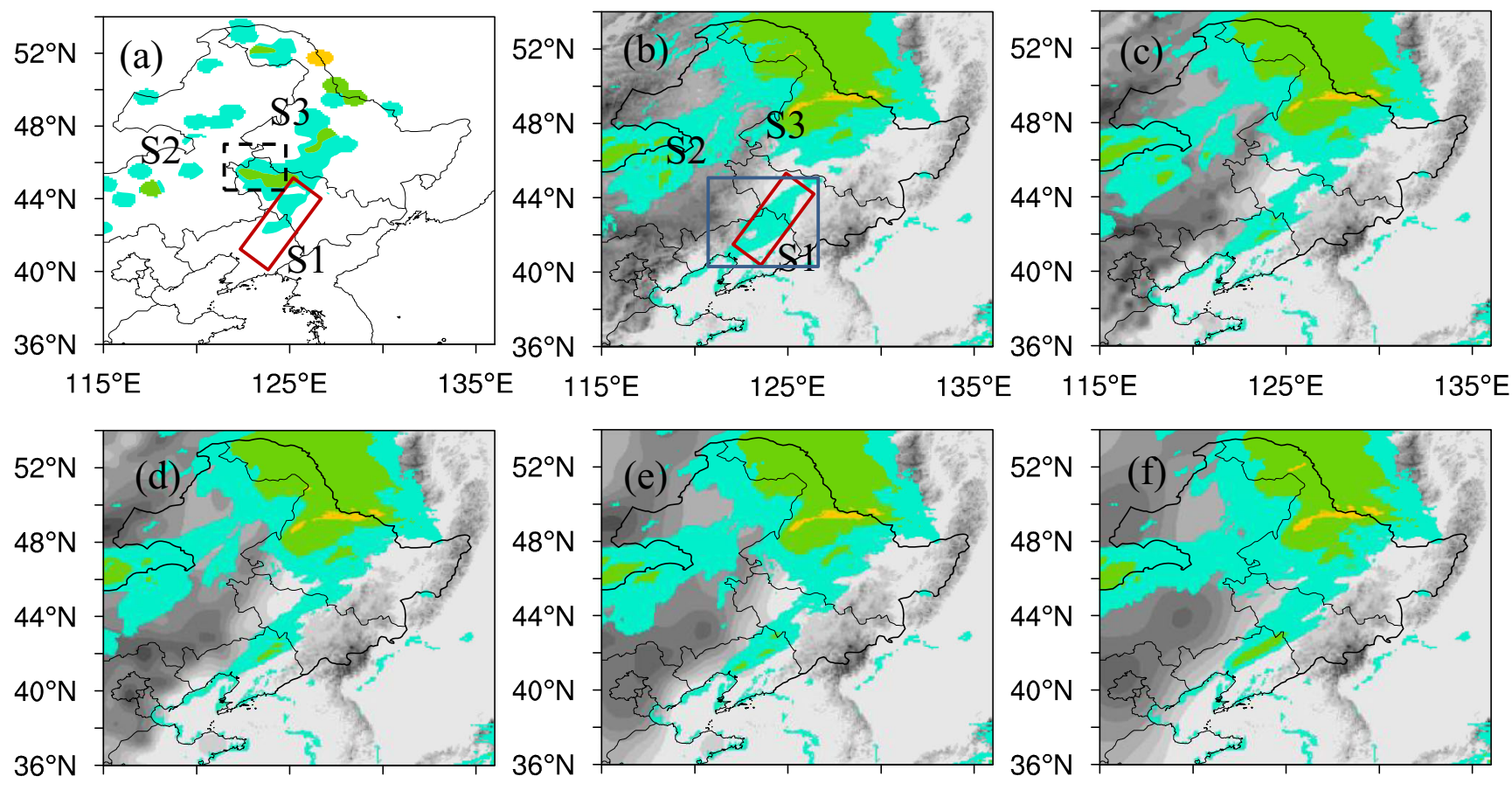

$115^{\circ} \mathrm{E}$

$125^{\circ} \mathrm{E}$

$135^{\circ} \mathrm{E} \quad 115^{\circ} \mathrm{E}$

$125^{\circ} \mathrm{E}$

$135^{\circ} \mathrm{E} \quad 115^{\circ} \mathrm{E}$

$125^{\circ} \mathrm{E}$

$135^{\circ} \mathrm{E}$
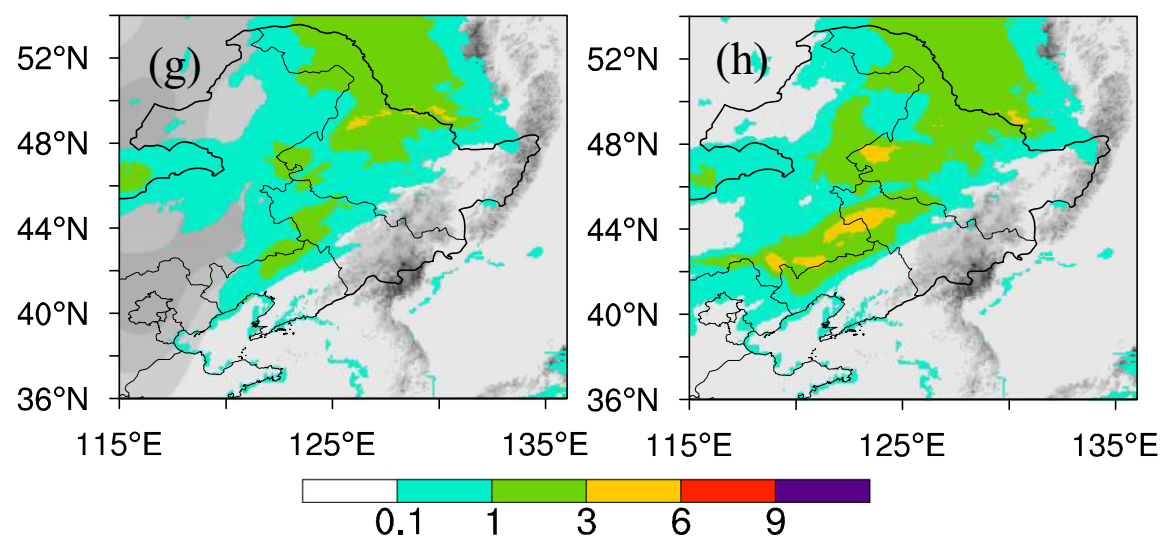

Fig. 4 Observed and simulated accumulated liquid-equivalent precipitation (color shading; units: mm) from 1700 UTC on 25 January 2017 to 0400 UTC on 26 January 2017. (a) observations and the (b) CTL, (c) T48, (d) T96, (e) T192, (f) T394, (g) Half T384 and (h) Flat upsm experiemtns (units: $\mathrm{m}$ ). The gray shading in the simulations represents the model terrain heights. The red boxes are the region in which the snowband formed; the dark blue box in part (b) indicates the region used to count the snowfall grids in Table 3; the black dashed box in part (a) indicates the region of snowfall that is not reflected in the simulations; S1, S2 and S3 indicate the three observed snowfall regions 
therefore unlikely to be associated with strong vertical motion. However, it is clear that mountains can create instabilities that favor the formation of bands.

By gradually smoothing the terrain of the Rocky Mountains, Schumacher et al. (2015) tested the relation between the small-scale topography, potential vorticity banners and leeside snowbands. They showed that the potential vorticity banners forming snowbands are not created by smallscale topographic features and both the potential vorticity banners and the associated snowbands disappeared after all the terrain had been removed. Sideresleben and Gohm (2016) showed that orographic potential vorticity banners developed at small-scale topographies within the European Alps. The release of the inertial instability associated with negative vorticity banners was crucial for the formation of convective bands leeward of the Alpine region.

The difference between these two studies of small-scale topographic features is probably because the inertial instability in Schumacher et al. (2015) was strongly related to the mid-level jet, whereas Kirshbaum and Schultz (2018) argued that inertial instability may not be a primary mechanism for the formation of downwind bands. Kirshbaum and Schultz (2018) suggested that inertial instability may reinforce the bands, but does not initiate them.

These studies on convective bands downstream of mountains show that there is much uncertainty about their formation and development, which involve interactions between weather systems and the topography, the conditions of upstream flow and the characteristics of the complex terrain. These uncertainties increase the difficulty of forecasting convective bands on the leeward side of mountains.

Li et al. (2021) investigated a snow burst that occurred in Northeast China on 26 January 2017. This unexpected snowfall event produced heavy snow, low visibility and high winds and led to numerous traffic accidents in Northeast China. The snowband that produced this snow burst formed leeward of the Greater Khingan Mountains along a northeast-southwestoriented cold front (red box in Fig. 1) and is a good example to study the formation of rainbands downstream of mountains. In contrast with the quasi-stationary rainband on the leeward side of the mountain discussed in Kirshbaum and Schultz (2018), the snowband moved eastward with the cold front until it reached the Changbai Mountains, where heavy snow fell on the windward side of the range (Fig. 1, colored dots). By reproducing this event in a high-resolution simulation, $\mathrm{Li}$ et al. (2021) explored the possible mechanisms for the enhanced snowfall over the Changbai Mountains by examining the instabilities and associated lifting mechanisms that are necessary for the development of snowbands. However, they did not explore the formation of snowbands downstream of the Greater Khingan Mountains.

The mechanisms by which the cold frontal snowband formed and how the upstream terrain affected this formation
Table. 3 Number of grids within the region of formation of the snowband (blue box in Fig. 4b) for different snowfall intensities

\begin{tabular}{llllllll}
\hline & CTL & T48 & T96 & T192 & T384 & Half_T384 & Flat_upsm \\
\hline$\geq 0.1 \mathrm{~mm}$ & 8844 & 9879 & 9550 & 9265 & 11,616 & 23,113 & 28,491 \\
$\geq 1 \mathrm{~mm}$ & 14 & 448 & 536 & 541 & 1557 & 5520 & 16,521 \\
$\geq 3 \mathrm{~mm}$ & 0 & 0 & 0 & 0 & 0 & 0 & 3594 \\
\hline
\end{tabular}

process are still unclear and this study aims to investigate these mechanisms. Clarification of these mechanisms is important for Northeast China because most of the plains are on the leeward side of the Greater Khingan Mountains. A thorough understanding of the formation of a cold frontal snowband under the influence of the Greater Khingan Mountains will help us to better monitor and provide early warnings of snowfall in Northeast China.

The paper is arranged as follows. Section 2 reviews the design of the numerical experiment in Li et al. (2021) (the control experiment) and six additional sensitivity experiments based on Li et al. (2021) with part, or all, of the upstream terrain removed to determine its exact role. Section 3 considers the validity of the control experiment in reproducing the formation of the snowband, with an analysis of the general influence of the upstream terrain on this process. Section 4 is a detailed study of the mechanism of formation of the snowband and how the upstream terrain modifies this mechanism. Section 5 presents a conceptual model of the formation of snowbands downstream of mountains.

\section{Numerical Experiments}

The control experiment used the same configurations as the high-resolution numerical simulation in Li et al. (2021). The simulation was conducted over Northeast China $\left(34-54^{\circ} \mathrm{N}\right.$, $110-138^{\circ} \mathrm{E}$ ) using version 3.8.1 of the Weather Research and Forecasting (WRF) model (Skamarock et al. 2008) and included only one domain. There were $(821 \times 751)$ horizontal grids with a grid spacing of $3 \mathrm{~km}$ and 51 vertical levels from the surface to $50 \mathrm{hPa}$. The initial and boundary conditions were provided by the hourly fifth generation global climate reanalysis dataset produced by the European Centre for

Fig. 5 Simulated composite maximum radar reflectivity (color shading; units: dBZ) for the CTL experiment at (a) 1745, (b) 1845, (c) 1930, (d) 2000, (e) 2130, (f) 2230 and (g) 2345 UTC on 25 January 2017 and (h) 0045, (i) 0145 , (j) 0300 and (k) 0400 UTC on 26 January 2017. The gray shading represents the model terrain heights. The red boxes indicate the region in which the snowband formed. The black lines indicate the convective lines in the snowband when they first appeared. A, B, C and $\mathrm{D}$ are the convective lines within the snowband. The straight red lines in part (d) indicate the locations of the cross-sections in the following figures 

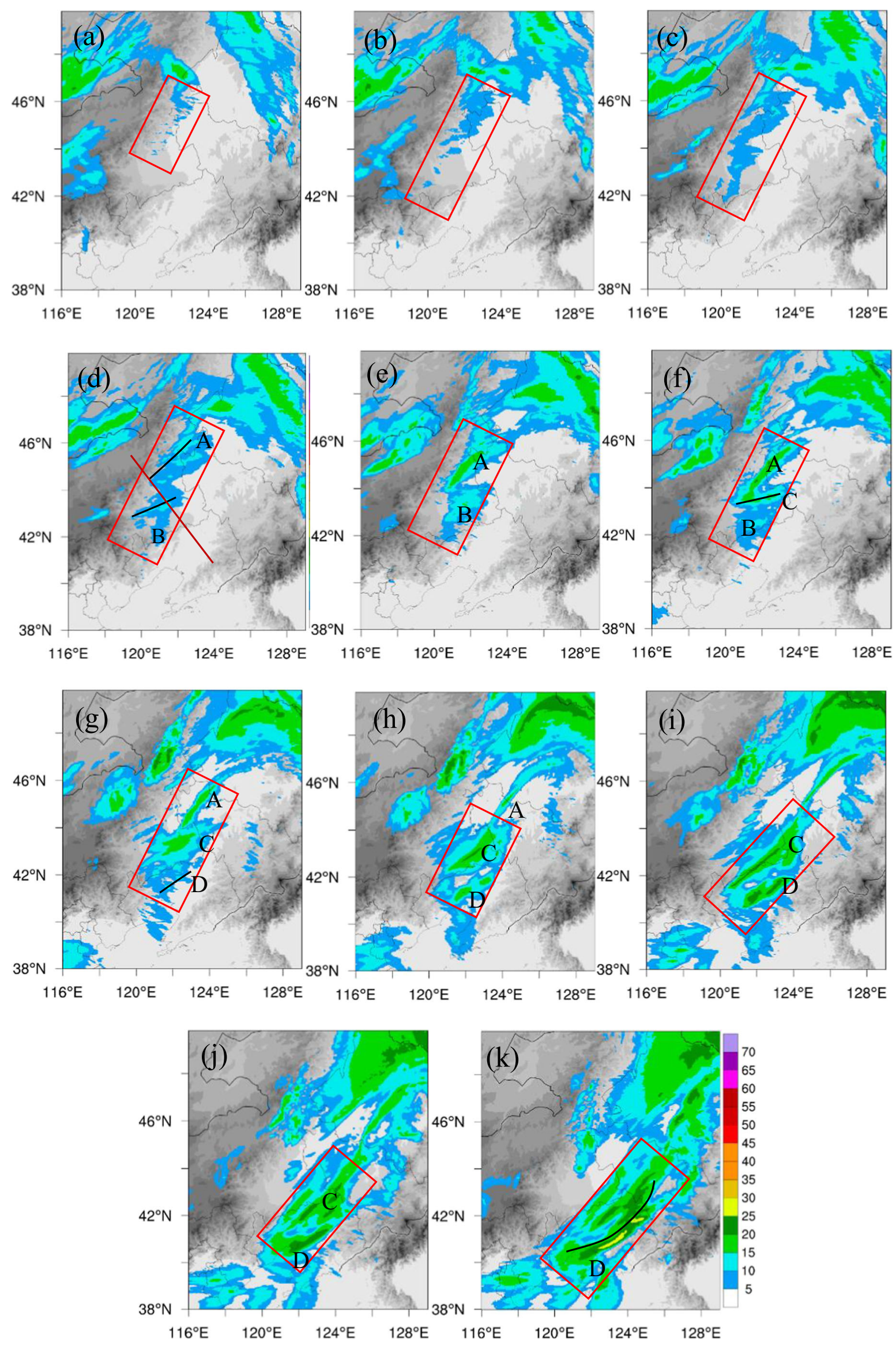

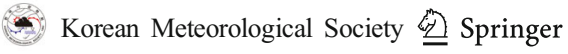



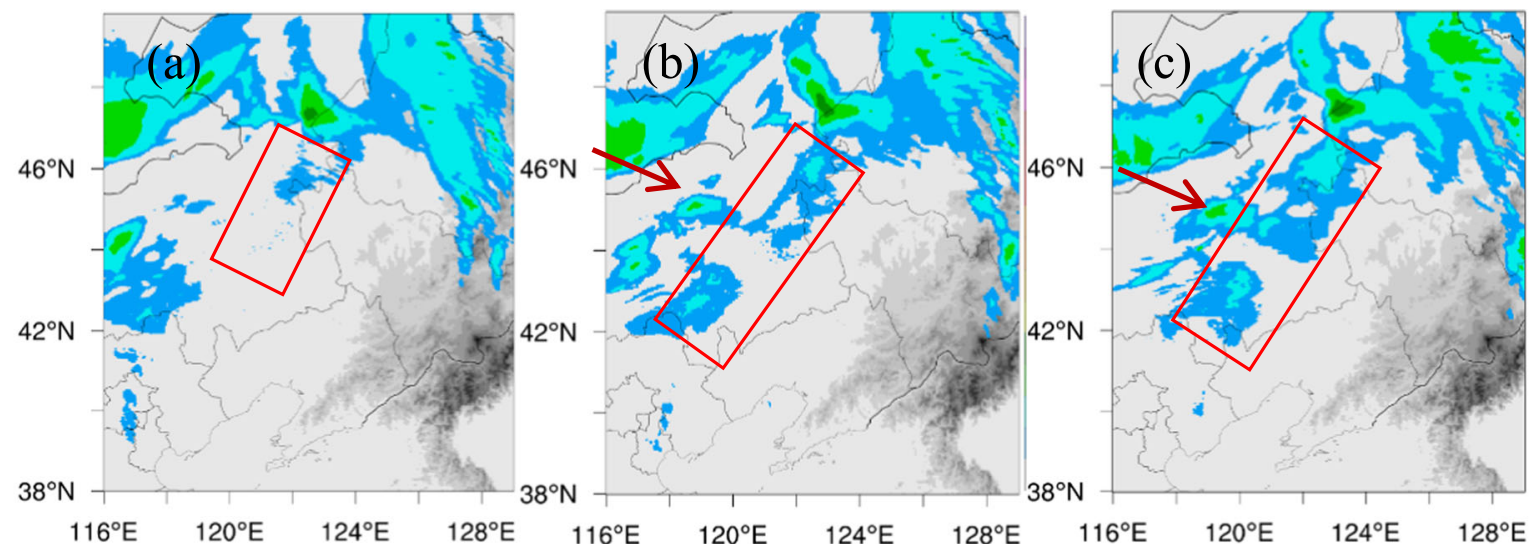

$116^{\circ} \mathrm{E} \quad 120^{\circ} \mathrm{E} \quad 124^{\circ} \mathrm{E} \quad 128^{\circ} \mathrm{E} \quad 116^{\circ} \mathrm{E} \quad 120^{\circ} \mathrm{E} \quad 124^{\circ} \mathrm{E} \quad 128^{\circ} \mathrm{E} \quad 116^{\circ} \mathrm{E} \quad 120^{\circ} \mathrm{E} \quad 124^{\circ} \mathrm{E} \quad 128^{\circ} \mathrm{E}$
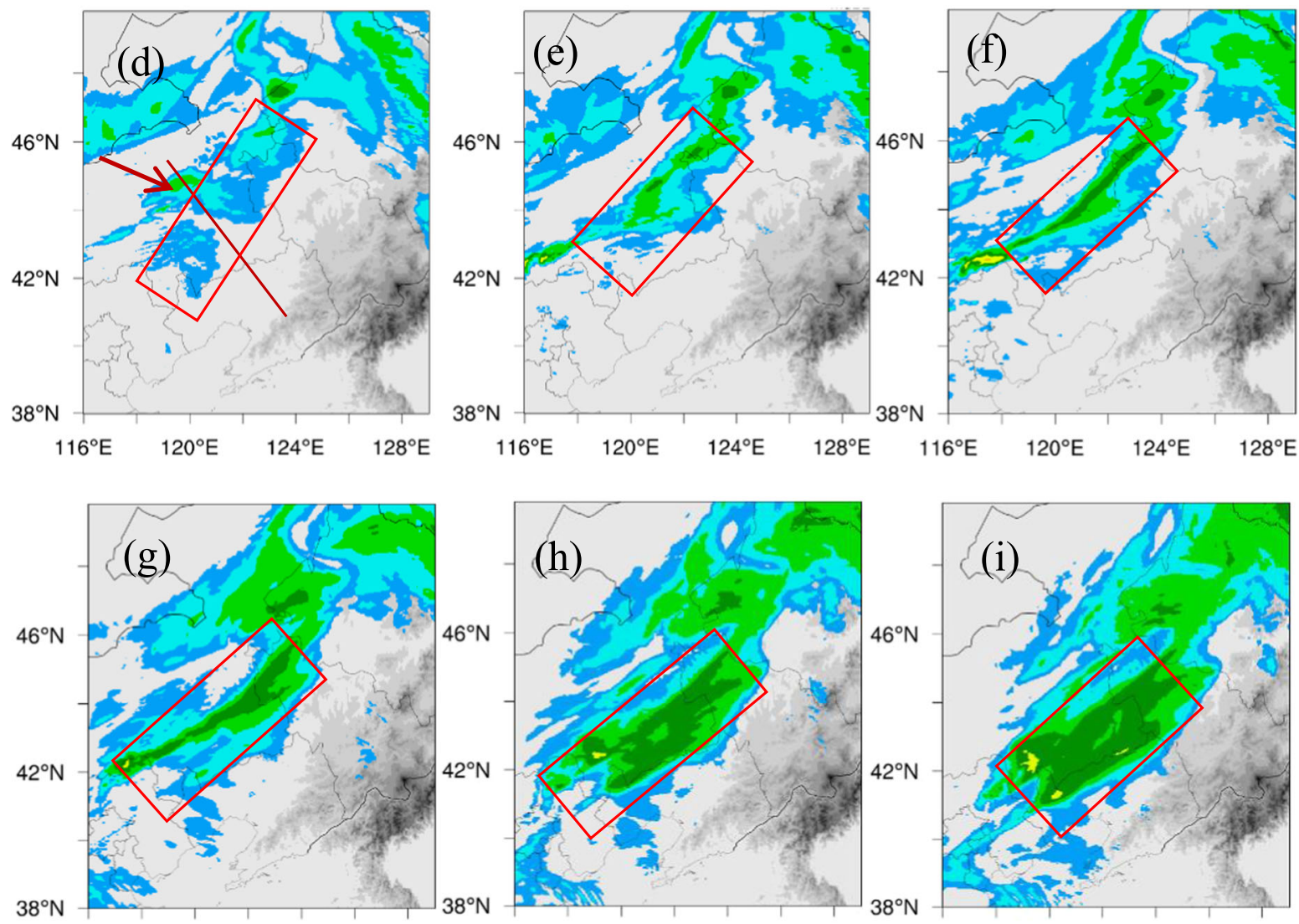

$116^{\circ} \mathrm{E} \quad 120^{\circ} \mathrm{E} \quad 124^{\circ} \mathrm{E} \quad 128^{\circ} \mathrm{E} \quad 116^{\circ} \mathrm{E} \quad 120^{\circ} \mathrm{E} \quad 124^{\circ} \mathrm{E} \quad 128^{\circ} \mathrm{E} \quad 116^{\circ} \mathrm{E} \quad 120^{\circ} \mathrm{E} \quad 124^{\circ} \mathrm{E} \quad 128^{\circ} \mathrm{E}$
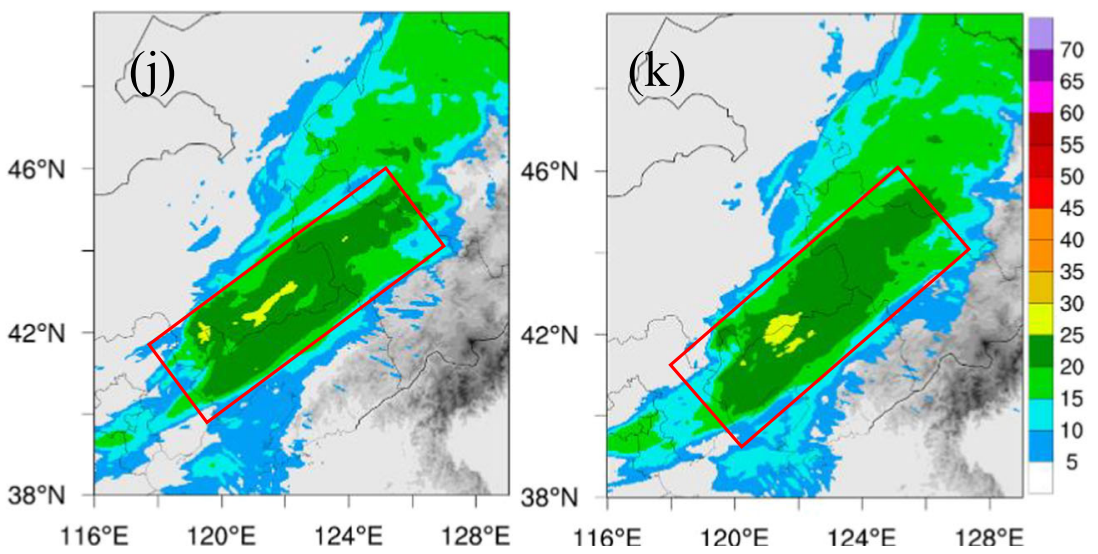

Springer - Korean Meteorological Society 
Fig. 6 Simulated composite maximum radar reflectivity (color shading; units: dBZ) for the Flat_upsm experiment at (a) 1745, (b) 1845, (c) 1930, (d) 2000, (e) 2130, (f) 2230 and (g) 2345 UTC on 25 January 2017 and (h) 0045, (i) 0145, (j) 0300 and (k) 0400 UTC on 26 January 2017. The gray shading represents the model terrain heights. The red boxes indicate the region in which the snowband formed. The straight red lines in part (d) indicate the locations of the cross-sections in the following figures

Medium-Range Weather Forecasts (the ECMWF ERA5 dataset) with a horizontal grid spacing of $\left(0.25^{\circ} \times 0.25^{\circ}\right)$ and 37 vertical levels. Table 1 presents the physical configurations of the experiment. The upper boundary absorbing option damp_opt $=3$ was used to avoid any non-physical wave reflection from the top of the model atmosphere (Klemp et al., 2008). The experiment was initialized at 1200 UTC on 25 January 2017 and integrated for $24 \mathrm{~h}$; the experiment ended earlier than that of Li et al. (2021) because our focus was only on the formation of the snowband. The files were output every $15 \mathrm{~min}$ to observe the continuous development of the snowband.

In addition to the control experiment, a series of sensitivity experiments that progressively removed the upstream terrain were conducted to reveal the influence of this terrain on the formation of the snowband. Here, the "upstream terrain" included all the terrain to the left of the blue dashed line in the model domain (Fig. 1). The Taihang Mountains in the southwestern region of snowband formation were included in the upstream terrain because of their important role in influencing the wind structure and supply of moisture in Northeast China.

The control (CTL) experiment used the $30 \mathrm{~s}$ topographic fields provided by the WRF, which were interpolated into the $3 \mathrm{~km}$ grids of the simulation domain. Wavelet analysis was applied to the interpolated $3 \mathrm{~km}$ topography and four smoothed topographic fields were obtained with wavelengths greater than 48, 96, 192 and $384 \mathrm{~km}$ (i.e., $2^{4}, 2^{5}, 2^{6}$ and $2^{7} \Delta x$ ). These smoothed topographies (Fig. 2b-e) were used to substitute the upstream terrain in the sensitivity experiments and are referred to as T48, T96, T192 and T384. On the basis of the T384 topography, two other simulations with half of the T384 upstream topography and a completely flat upstream land surface were also conducted to evaluate the importance of the large-scale topography (Fig. $2 \mathrm{f}$ and g) compared with the small-scale topography (Fig. 2b-e). These two simulations are referred to as Half_T384 and Flat_upsm, respectively. Table 2 summarizes these experiments.

\section{Verification of the Control Experiment and the Impact of Terrain}

\subsection{Large-Scale Environmental Conditions}

Figure 3 compares the large-scale environment during the development of the snowband at 0000 UTC on 26 January
2017 with the ECMWF ERA5 reanalysis dataset $\left(0.25^{\circ} \times\right.$ $0.25^{\circ}$ horizontal grid spacing) and the output of the CTL experiment. In the ECMWF reanalysis dataset (Fig. 3a-c), the snowband (red box) forms along a cold front (thick black curved line), with the exit region of the upper level jet (ULJ) at high levels (Fig. 3a, shading), the trough at mid-levels (Fig. $3 \mathrm{a}$, red curved line), the strong low-level jets (LLJs) at low levels (Fig. 3b, shading) and an extratropical cyclone at the surface (Fig. 3b, black contours). The superposition of the ULJ and low-level cold front provides a favorable environment for upward motion ( $\mathrm{Li}$ et al., 2021). Two LLJs were present at low levels and the snowband formed in an unsaturated environment (Fig. 3c) just prior to the cold front between the two LLJs (Fig. 3b). The southwesterly LLJ in front of the cold front and to the south of the surface cyclones transported moisture into Northeast China from low latitudes. The northwesterly LLJ, located over the Greater Khingan Mountains, may have produced dynamic instabilities on its anticyclonic flank, just behind the cold front, and influenced the formation of the snowband (Schumacher et al. 2010).

The control experiment reproduced the environment for the formation of the snowband well (Fig. 3d-f). All the key elements-including the location and intensity of the ULJ and the LLJ, the cold front and the humidity distributionare very similar to those in the ECMWF analyses. This provides a basis to reproduce the process for the formation of the snowband.

\subsection{Simulated Snowfall}

Apart from the large-scale environment, other evidence to validate the performance of the CTL experiment was obtained from the simulated amount of accumulated precipitation, which was analyzed by Li et al. (2021). We analyzed the ability of the CTL experiment to simulate the snowfall event, focusing on the period in which the snowband formed.

The definition of "snowband formation" needs some clarification. This is similar to the initiation of deep moist convection, for which the $35 \mathrm{dBz}$ radar reflectivity is used as a criterion (Weckwerth and Parsons 2016; Abulikemu et al. 2019), indicating that the convection needs to be strong enough to be defined as deep moist convection. However, it is difficult to use the radar reflectivity as the criterion for a snowband because the radar reflectivity not only needs to be strong enough for snow to form, but also needs to form a well-organized and persistent banded structure. We therefore use the $1 \mathrm{~h}$ accumulated snowfall amount to define the formation of the snowband - that is, when the snowfall on the ground develops a banded structure, the snowband is considered to have formed. The criterion for this band is $0.1 \mathrm{~mm}$ snowfall in $1 \mathrm{~h}$. With this criterion, the snowband in the CTL experiment formed at 0400 UTC on 26 January 2017. 
Figure $4 \mathrm{a}$ and $\mathrm{b}$ shows the snowfall from the observations and the CTL experiment during the time period from 1700 UTC on 25 January 2017 to 0400 UTC on 26 January 2017 - that is, from the presence of weak snowfall to the formation of a well-organized snowband. Figure $4 \mathrm{~b}$ shows that three areas of snowfall (indicated by S1, S2 and S3) appear in the CTL experiment. $\mathrm{S} 1$ is the cold frontal snowband in Jilin and Liaoning provinces studied here. S2, west of the Great Khingan Mountains, is related to the $500 \mathrm{hPa}$ trough. S3 is related to the surface cyclone north of Heilongjiang Province.

Comparing Fig. 4b with Fig. 4a, it can be seen that the structures of the areas of snowfall in the observations are not as clear as those in the CTL experiment as a result of the sparse distribution of observational stations in the mountains. However, there are similarities between the simulation and observations, such as the northeast-southwest-oriented banded structure of the initial snowband in the red boxes (S1) and the general sketches of the S2 and S3 areas. This further indicates the success of the CTL simulation.

In addition to these three areas of snowfall, the observations in Fig.4a also show a local area of snowfall to the northwest of the initial snowband enclosed by the dashed box in Fig. 4a, which the CTL simulation did not produce. However, this local snowfall did not seem to influence the subsequent development of the snowband and we can therefore use the numerical simulation for further analyses.

\subsection{Negative Effects of the Upstream Terrain on the Formation of the Snowband}

Table 2 lists the snowband formation times for all experiments using the criterion defined here. A small change or smoothing of the terrain did not change the time of formation of the cold frontal snowband - the T48, T96 and T192 experiments all gave the same formation time as the CTL experiment. However, a larger modification of the terrain - such as in the T384, Half_T384 and Flat_upsm experiments_-advanced the formation time of the snowband. The snowband in the Flat_upsm experiment formed $4 \mathrm{~h}$ earlier than that in the CTL experiment.

The negative effects of the small-scale topography can be evaluated by comparing Fig. $4 \mathrm{c}-\mathrm{h}$ with Fig. $4 \mathrm{~b}$. The removal of terrain with wavelengths $<48 \mathrm{~km}$ (Fig. $4 \mathrm{c}$ ), $<96 \mathrm{~km}$ (Fig. 4d), $<192 \mathrm{~km}$ (Fig. 4e) and $<384$ km (Fig. 4f) leads to only small changes in the region of banded snowfall, but the intensity of the snowband gradually strengthens. Table 3 shows the counts of the grids with snowfall amounts $>0.1$, $>1$ and $>3 \mathrm{~mm}$ in the region of the blue box (Fig. 4b) from 1700 UTC on 25 January 2017 to 0400 UTC on 26 January 2017 in every experiment. The number of grid points with $>0.1 \mathrm{~mm}$ precipitation is roughly comparable between the CTL experiment and the other runs, but the number of grids with $>1 \mathrm{~mm}$ of precipitation increases as the terrain becomes smoother. Compared with experiments T48, T96, T192 and T384, which make relatively minor modifications to the terrain, the reduction in terrain height in T384 to onehalf (Half_T384) and the full reduction in all the upstream terrain (Flat upsm) lead to larger changes in the snowband. The snowband in Fig. $4 \mathrm{~g}$ and $\mathrm{h}$ is much wider and stronger than that in Fig. 4b. In Table 3, if we consider Flat upsmCTL as the influence of the upstream terrain, then the upstream terrain shrinks the area with precipitation $>0.1 \mathrm{~mm}$ by nearly $70 \%$ and the areas with precipitation $>1$ and $>$ $3 \mathrm{~mm}$ decrease by nearly $100 \%$. This negative effect of the upstream terrain is different from that for the "downwind bands" discussed in Schumacher et al. (2015), Sideresleben and Gohm (2016) and Kirshbaum and Schultz (2018), in which orographic effects had major roles in the formation of snowbands without any evident influence from cold fronts.

We used the CTL and Flat_upsm experiments to analyze the process for the formation of the snowband and the negative effects of the upstream terrain. The Flat_upsm experiment showed the influence of large variations in terrain on precipitation in the downstream regions. Comparison of the Flat_upsm and CTL experiments helps to separate out the orographic effects and the effects of weather systems such as the cold front.

\section{Ingredients-Based View of the Mechanism of Formation of the Snowband}

Banded precipitation is commonly observed in association with frontal zones and many mechanisms have been proposed to explain its formation (e.g., Bennetts and Hoskins 1979; Clark et al. 2002; Kawashima 2016). Among these mechanisms, conditional symmetrical instability (CSI) and frontogenesis are the most frequently cited. To clearly understand the relation between $\mathrm{CSI} /$ frontogenesis and banded precipitation, Schultz and Schumacher (1999) extended an ingredient-based methodology for deep moist convection (Doswell et al. 1996) to moist slantwise convection, in which instability, moisture and lift are the three conditions necessary to produce moist slantwise convection.

Here, the instability indicates CSI and frontogenesis is seen as the mechanism that lifts the air to a free convection level. However, in real examples, many banded precipitation events appear without CSI, such as the events reported by Trap et al. (2001), Novak et al. (2004), Jurewicz and Evans (2004) and Luo et al. (2018). In these examples, conditional instability in a frontogenetic environment is responsible for the precipitation bands. When the atmosphere is not saturated, inertial instability can also have a role. The relationship between inertial instability and convection is not as clear as the relationships between CSI (or conditional instability) and convection, 
although there is ongoing research on the release of inertial instability, the circulation produced by inertial instability, and the relationship between inertial instability and mesoscale systems. Schultz and Knox (2007), Novak et al. (2008) and Schumacher et al. (2010) reported the presence of inertial instability during the formation of snowbands. The horizontal divergence produced by the release of inertial instability is considered to be one of the mechanisms by which inertial instability induces banded convection (Siedersleben and Gohm 2016).

Previous studies have shown that, despite the clear ingredients required to produce banded precipitation, real examples are much more complex, especially in the presence of complex terrain. We adopted this ingredients-based method to analyze the formation of snowbands with and without terrain in the CTL and Flat_upsm experiments. The conditions for all possible instabilities for banded precipitation are:

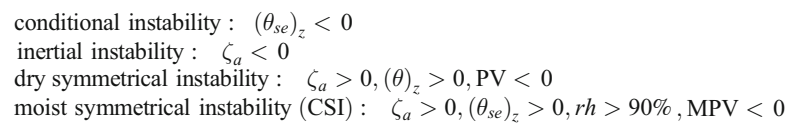

where $\left(\theta_{s e}\right)_{z}=d \theta_{s e} / d z,(\theta)_{z}=\mathrm{d} \theta / d z, \theta_{\text {se }}$ is the equivalent potential temperature, $\theta$ is the potential temperature, $\zeta_{\mathrm{a}}$ is the absolute vertical vorticity, $r h$ denotes the relative humidity, $\mathrm{PV}$ is potential vorticity defined by $\mathrm{PV}=\left(\boldsymbol{\omega}_{\mathrm{a}} \cdot \nabla \theta\right) / \rho$, MPV is the moist potential vorticity defined by MPV $=\left(\boldsymbol{\omega}_{\mathrm{a}} \cdot \nabla \theta_{\mathrm{se}}\right) / \rho, \rho$ is the air density, $\omega_{\mathrm{a}}$ is the three-dimensional vorticity vector. The total wind was used to calculate $\zeta_{\mathrm{a}}, \mathrm{PV}$ and MPV, which is discussed in Schultz and Knox (2007) and Schumacher et al. (2010).

\subsection{Snowband Formation in the CTL and Flat_upsm Experiments}

Figures 5 and 6 present the formation processes for the whole snowband in the CTL and Flat_upsm experiments, respectively. There is a well-organized snowband at 0400 UTC on 26 January 2017 in Fig. 5k in the CTL simulation and at 2345 UTC on 25 January 2017 (about 0000 UTC on 26 January 2017 ) in Fig. $6 \mathrm{~g}$ in the Flat upsm simulation.

In Fig. 5a-d and 6a-d (i.e., from 1745 to 2000 UTC on 25 January 2017), both the CTL and Flat upsm experiments present weak reflectivity bands in the region of snowband formation enclosed by the red boxes. However, in the subsequent development from 2000 to 2345 UTC on 25 January 2017 (Fig. 6e-g), the radar reflectivities in the Flat_upsm experiment rapidly intensify and form a continuous, well-organized banded structure nearly $1000 \mathrm{~km}$ long from northeast to southwest. By contrast, the development of the snowband in the CTL experiment is very slow. The two new lines of convection (C and D), which organize into the snowband (Fig. $5 \mathrm{~g}-\mathrm{k}$ ),
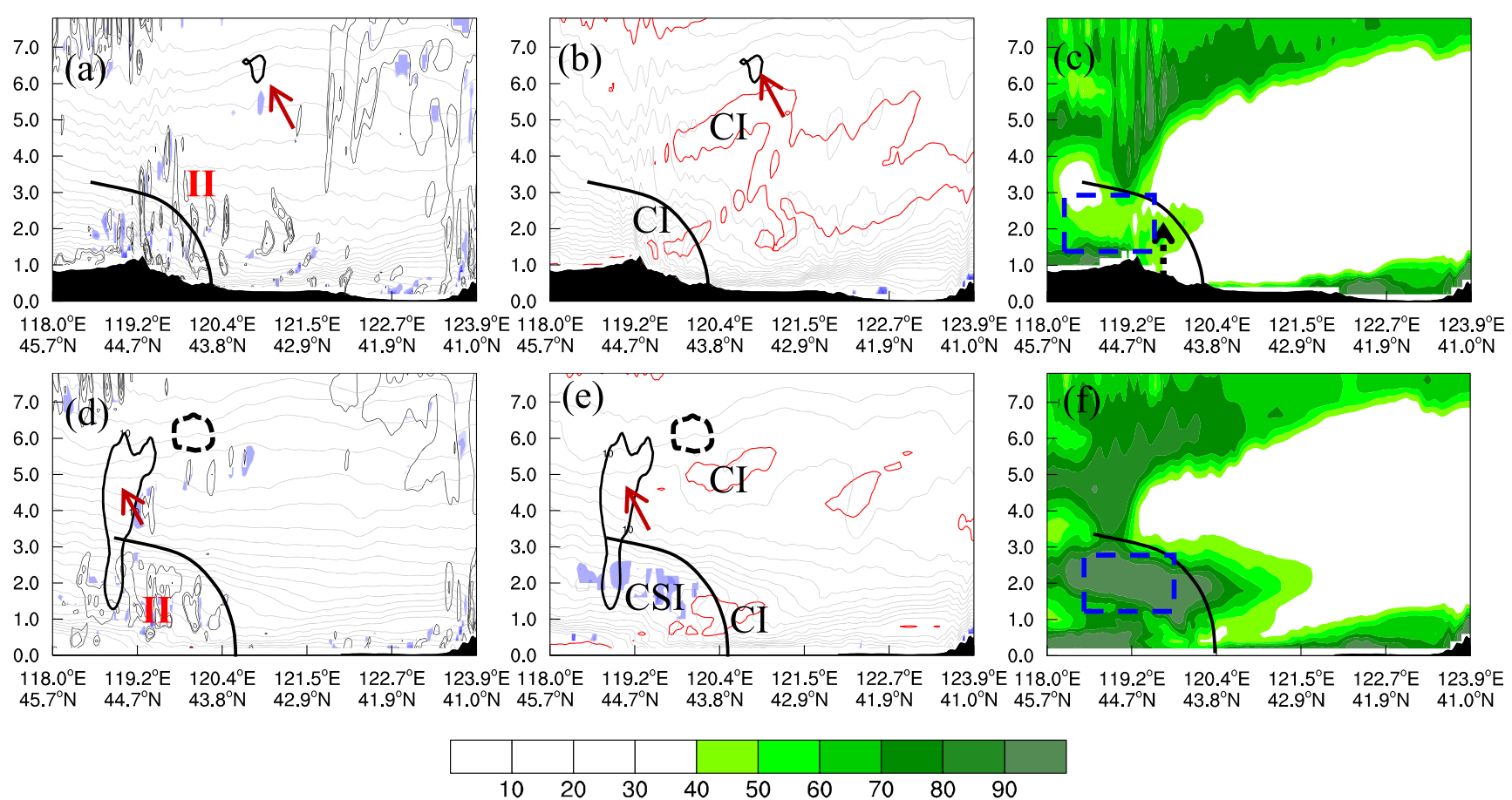

Fig. 7 Vertical cross-sections of the (a, d) inertial instability (black line) and dry symmetrical instability regions (color shading), (b, e) the CSI (color shading) and conditional instability (red solid line) regions and (c, f) the relative humidity (units: \%) along the line shown in Fig. 5d at 2000 UTC on 25 January 2017 in the CTL experiment (upper panels) and the Flat_upsm experiment (lower panels). The thick black contours in parts (a) and (b) and the dashed contours in parts (d) and (e) are the $10 \mathrm{dBZ}$ simulated radar reflectivity; the gray contours in parts (a) and (d) are the potential temperatures and the gray contours in parts (b) and (e) are the saturated equivalent potential temperatures. The cold fronts are indicated by the thick curved black lines. The red arrows highlight the location of some radar reflectivities. The blue dashed boxes indicate the moisture distribution around the region in which the snowband formed. The black dashed arrow indicates the increase in moisture with height 
develop at 2230 UTC in the CTL experiment (Fig. 5f). The band in the CTL experiment is still forming (Fig. 5 $\mathrm{h}-\mathrm{k}$ ) when the snowband in the Flat upsm experiment is gradually growing to form a mature band and producing banded snowfall (Fig. $6 \mathrm{~h}-\mathrm{k}$ ).

The weak band stage before 2000 UTC on 25 January 2017 and the formation of the snowband after 2000 UTC are

(a)

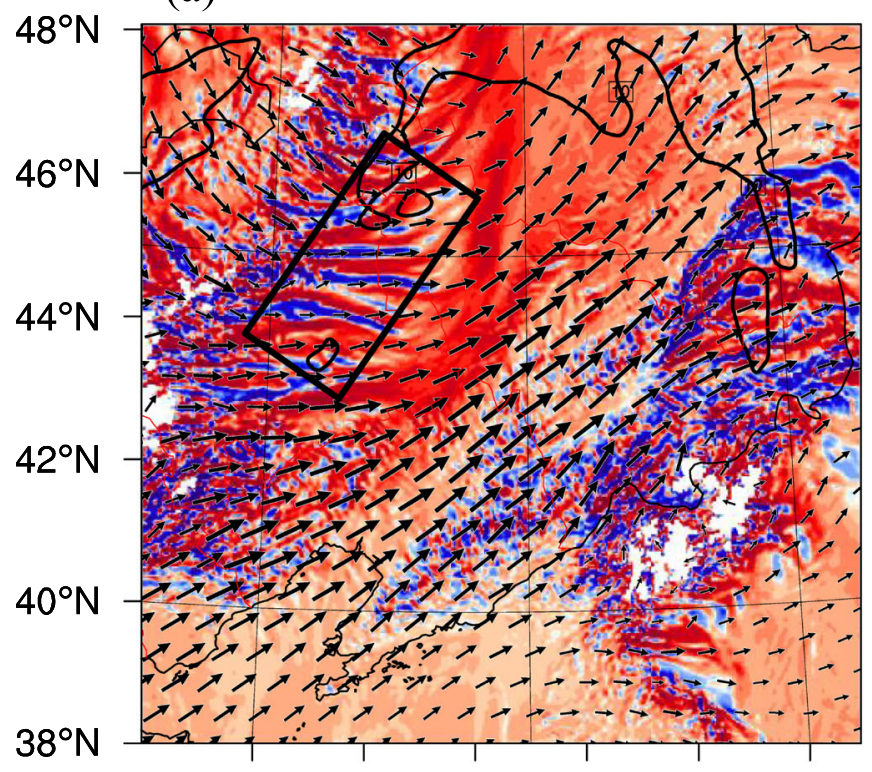

$120^{\circ} \mathrm{E}$ $124^{\circ} \mathrm{E}$

$128^{\circ} \mathrm{E}$

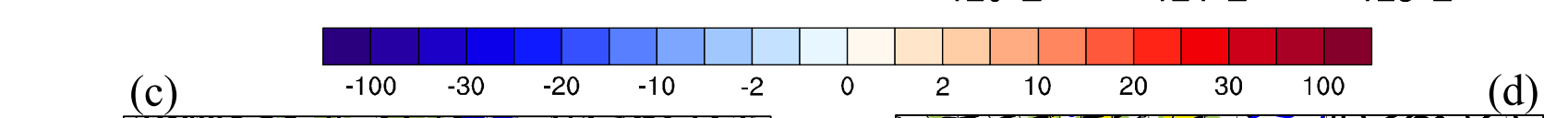

$115^{\circ} \mathrm{E} \quad 120^{\circ} \mathrm{E} \quad 125^{\circ} \mathrm{E} \quad 130^{\circ} \mathrm{E} \quad 135^{\circ} \mathrm{E}$

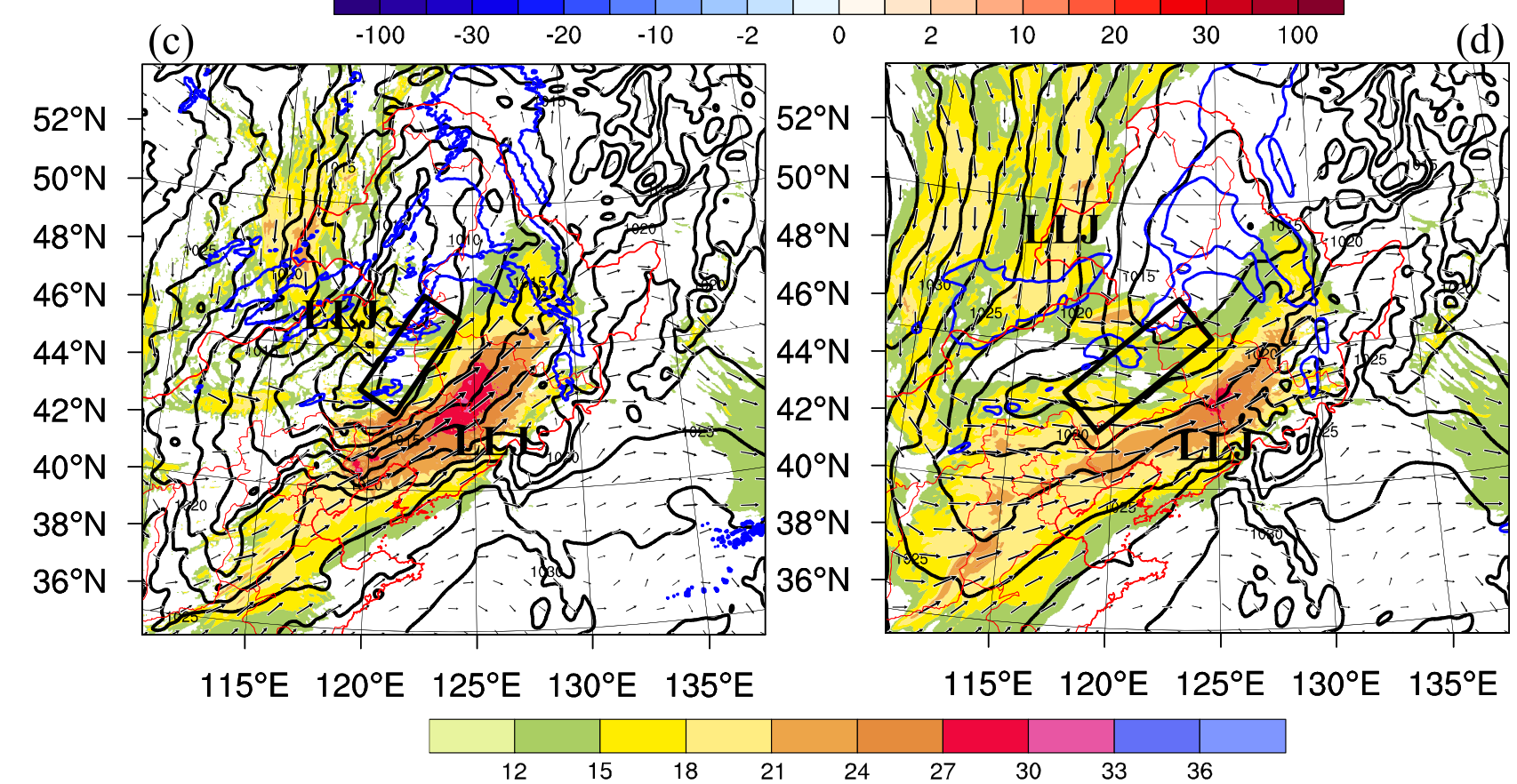

analyzed separately to show the mechanism responsible for the difference in the CTL and Flat_upsm experiments.

\subsection{Weak Bands before 2000 UTC on 25 January 2017}

Figure 7 shows the vertical distributions of moisture and instability along the red lines in Fig. 5d and 6d, which crossed

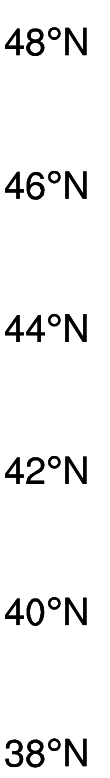

(b)

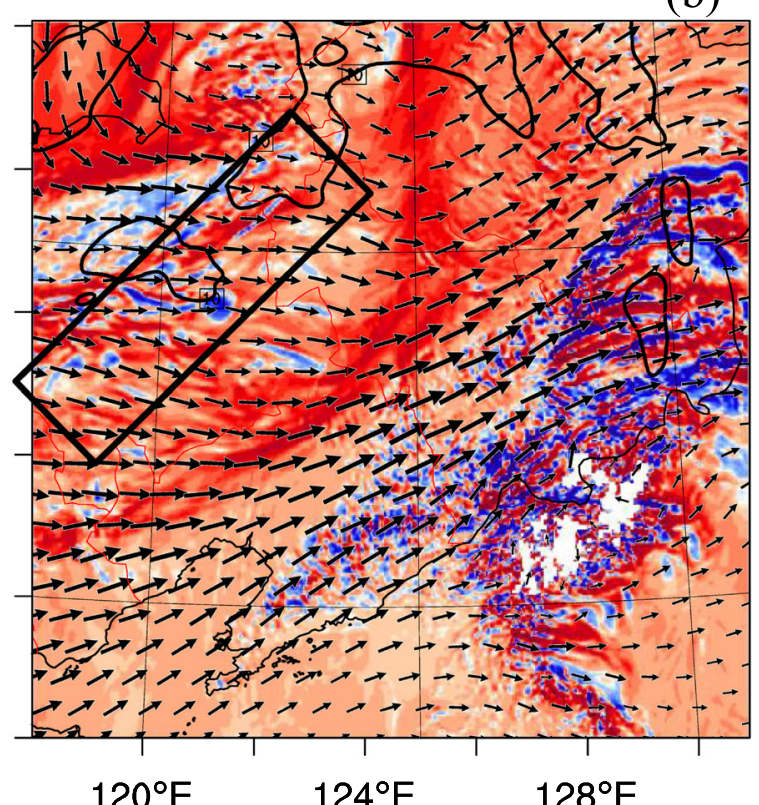

Fig. 8 (a, b) Absolute vertical vorticity (shading) and (c, d) geopotential height (black contours) and total wind speed $>10 \mathrm{~m} \mathrm{~s}^{-1}$ (shading) at $850 \mathrm{hPa}$ at $2000 \mathrm{UTC}$ on 25 January 2017 for the CTL experiment (left-hand column) and the Flat_upsm experiment (right-hand column).

The arrows are the horizontal wind vectors at $850 \mathrm{hPa}$. The black contours in parts (a) and (b) and the blue contours in parts (c) and (d) are the 10 and $20 \mathrm{dBZ}$ radar reflectivities. The black boxes indicate the future areas of snowband formation

Springer - Korean Meteorological Society 
the weak reflectivity bands at 2000 UTC on 25 January 2017.

Weak reflectivities (indicated by the red arrows in Fig. 7a and b) appear on the leeward side of the Greater Khingan Mountains at a height of roughly $6 \mathrm{~km}$ in the CTL experiment.
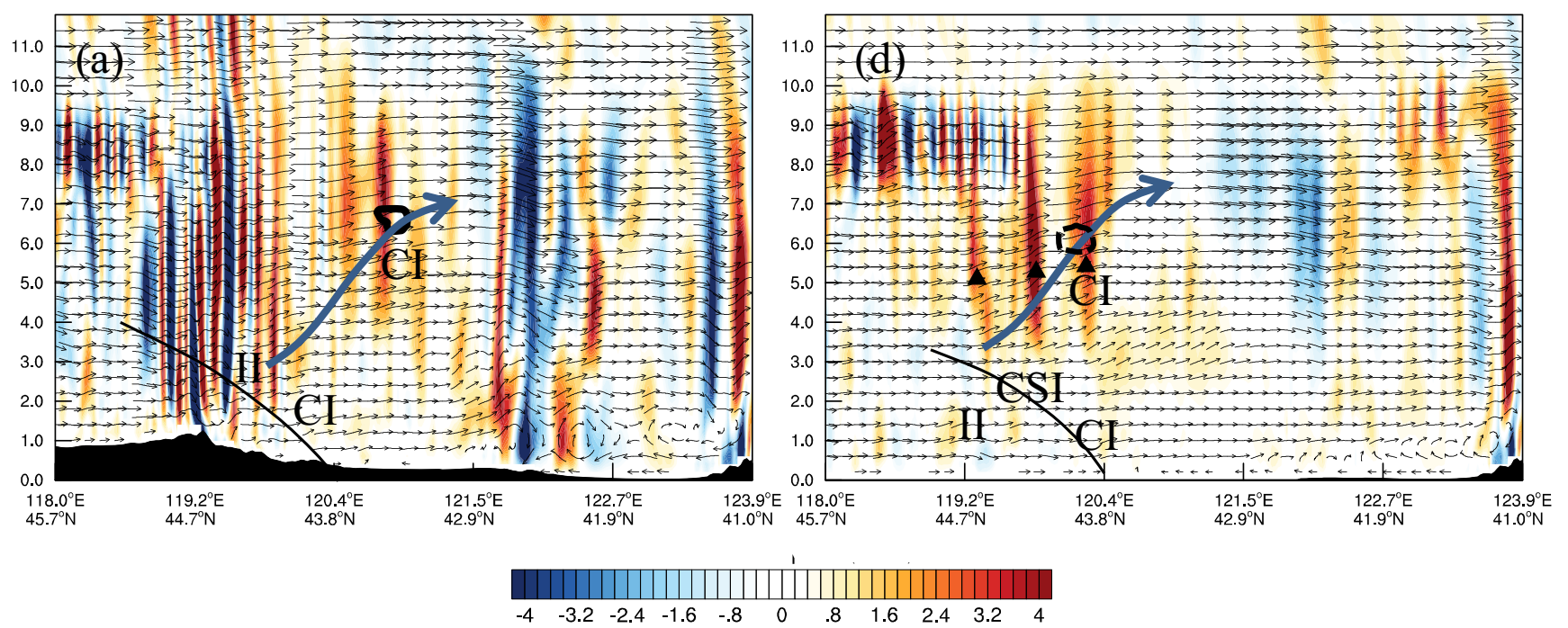

$\prod_{0}^{1}$
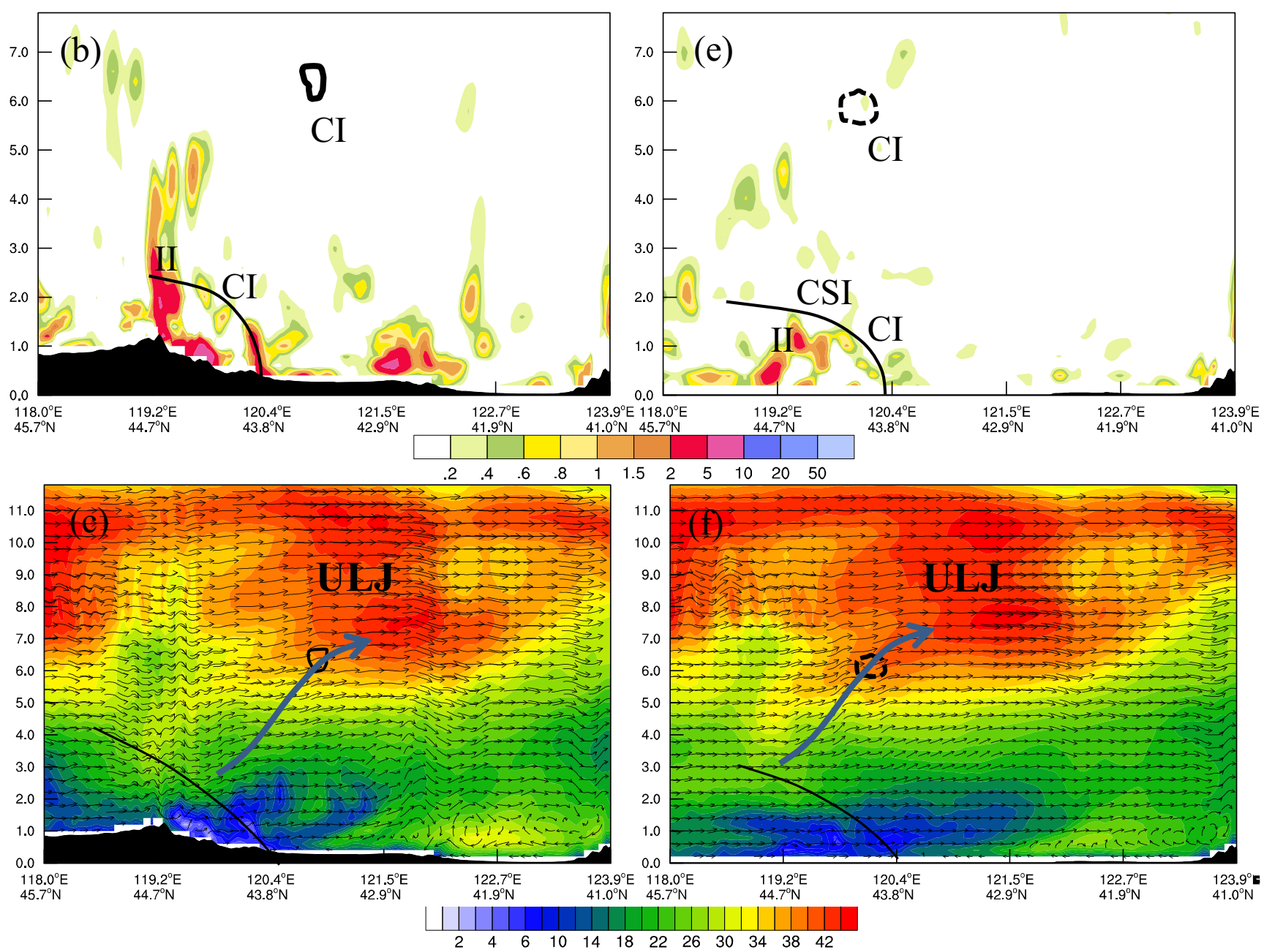

Fig. 9 Vertical cross-sections of the (a, d) vertical velocity (units: $\left.10^{-1} \mathrm{~m} \mathrm{~s}^{-1}\right),(\mathbf{b}, \mathbf{e})$ frontogenesis (shading) and (c, f) horizontal wind speed (units: $\mathrm{m} \mathrm{s}^{-1}$ ) along the same line as in Fig. 7 at 2000 UTC on 25 January 2017 in the CTL experiment (left-hand column) and Flat_upsm experiment (right-hand column). The thick black (dashed) contours are the $10 \mathrm{dBZ}$ simulated radar reflectivity. The blue curved arrows indicate the ascending branch of the jet front circulation, and the thick curved black lines indicate the cold front 
These reflectivities are located just above a mid-layer conditional instability region (Fig. 7b, red contours) resulting from the moist layer (high relative humidity in Fig. 7c) at heights between 5 and $6 \mathrm{~km}$.

At the low levels, there are other instabilities over the Greater Khingan Mountains, mainly inertial instability and conditional instability. Conditional instability (Fig. 7b) is a result of the increase in moisture with height (Fig. 7c, dashed arrow) immediately downstream of the mountain ranges. The inertial instability over the mountains (Fig. 7a) is caused by the interaction of the northwesterly LLJ and the topography. To illustrate the source of the low-level inertial instabilities, Fig. 8 shows the horizontal distributions of the absolute vorticity and strong wind speeds at $850 \mathrm{hPa}$ at $2000 \mathrm{UTC}$ for the two experiments. Figure $8 \mathrm{a}$ and c show that, in the CTL experiment, the interaction of the northwesterly LLJ over the western flank of the surface cyclones and the terrain generates vorticity banners on the eastern leeward side of the Greater Khingan Mountains (black box). This structure is similar to the potential vorticity (or vorticity) banners reported by Sidersleben and Gohn (2016) downstream of the Alps, which are usually generated by flow separation or gravity wave breaking induced by cross-mountain flow (Schär et al. 2003; Jiang et al. 2003; Gohm and Mayr 2005). Sidersleben and Gohn (2016) argued that these vorticity banners produced inertial instabilities, which result in convergence and uplift, releasing conditional instability and forming multiple cloud bands downstream of the Alps. Their roles will be monitored in our current cold frontal snowband.

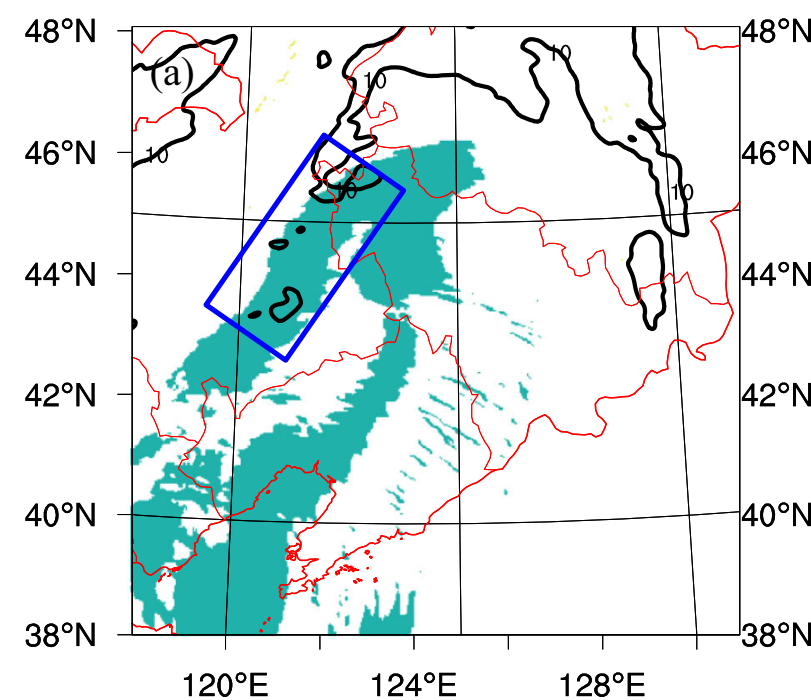

(c)

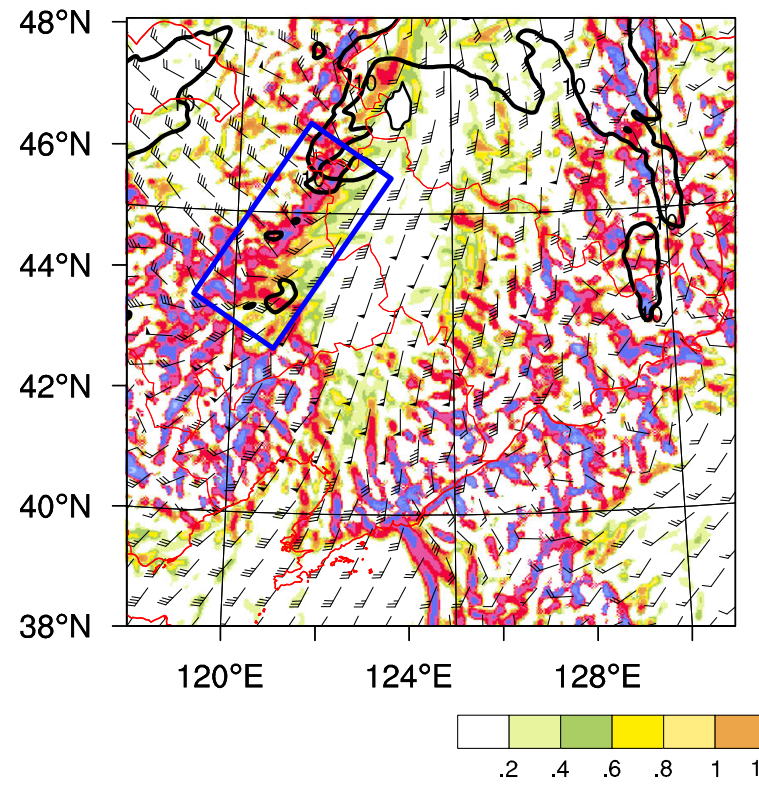

Fig. 10 Horizontal distributions of the (a, b) mid-level conditional instability at $\eta=0.50$ model height (green shading) and (c, d) frontogenesis at the near-surface $\eta=0.97$ level at 2000 UTC on 25 January 2017 for the

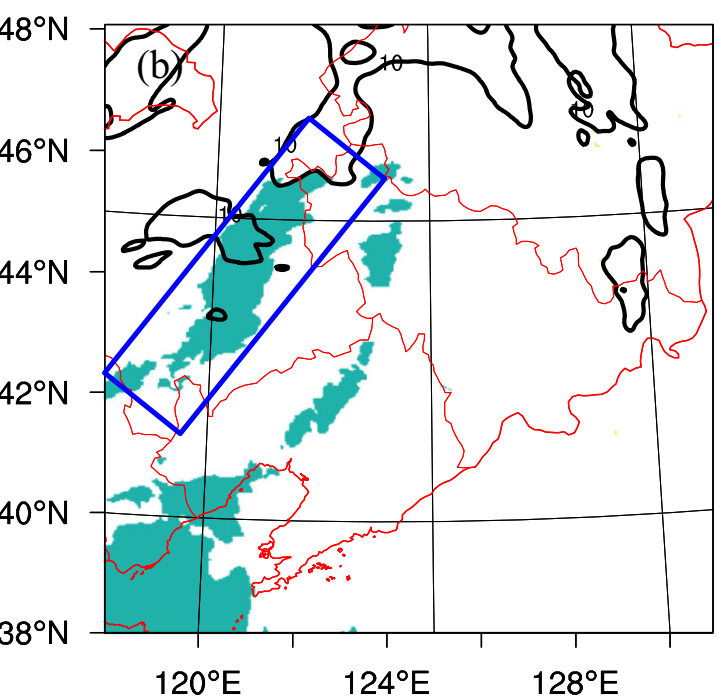

(d)

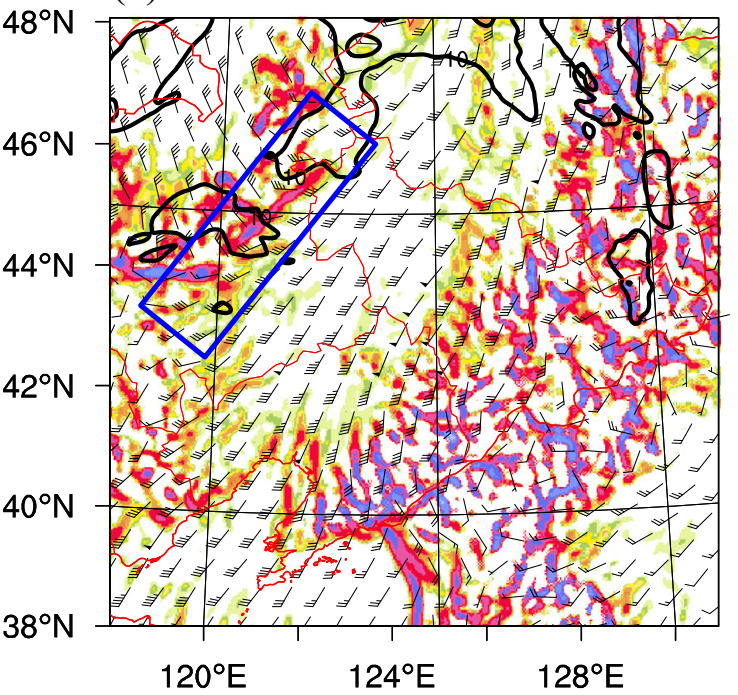

CTL experiment (left-hand column) and the Flat_upsm experiment (righthand column). The blue boxes indicate the region in which the snowband formed 
Compared with the CTL experiment, a major difference in the Flat upsm experiment is that the reflectivities present large vertical extensions, indicated by the red arrows in Fig. $7 \mathrm{~d}$ and e. However, these reflectivities result from an eastward-moving convective system (Fig. 6b-d, red arrows), which is not present in the region of formation of the snowband and is therefore beyond the scope of this study. To distinguish this moving reflectivity, Fig. $7 \mathrm{~d}$ and e use dashed contours to denote the reflectivities formed within the snowband region. The instabilities in the Flat_upsm experiment are similar to those in the CTL experiment, including the mid-layer conditional instability (Fig. 7e) under weak reflectivities (dashed contours), low-level inertial instabilities and conditional instability (Fig. $7 \mathrm{~d}$ and e).

However, the mechanisms of generation of low-level inertial instabilities and conditional instability are different from those in the CTL experiment. The low-level conditional instability in Fig. $7 \mathrm{e}$ is caused by an elevated moist layer $1-2 \mathrm{~km}$ in height (Fig. 7f, blue dashed box), which is absent in the CTL experiment (Fig. 7c, blue dashed box). This layer also produces a small region of CSI near the conditional instability region (Fig. 7e). The inertial instabilities in Fig. 7d are generated by the northeasterly LLJ without the influence of topography (Fig. 8b and d). No evident vorticity banners are found in the region of formation of the snowband in the Flat_upsm experiment (Fig. 8b), resulting in the intensities of the inertial instability being much weaker and less organized than in the CTL experiment.

The presence of these instabilities does not indicate that they will contribute to the formation of the snowband because, according to the ingredient-based view, they need a proper lifting mechanism to release the instabilities. To illustrate this possible lifting mechanism, Fig. 9 shows the vertical motion, frontogenesis and ULJ along the same lines.

In the Flat_upsm experiment (Fig. 9d-f), the weak reflectivities at 2000 UTC on 25 January 2017 appear in an environment with a widespread wave-like distributed ascent over the cold front under the entrance region of the ULJ, indicating a coherent jet front secondary circulation (thick blue curved ascending arrow). Three ascending centers are observed (Fig. 9d, black shaded triangles) within the wide ascent regions and weak reflectivities form in only one of them.

The generation of these ascending centers results from two processes: frontogenesis and small-scale gravity waves near the ULJ. The regions of frontogenesis are distributed along the cold front in the lower troposphere below a height of $3 \mathrm{~km}$ (Fig. 9e)
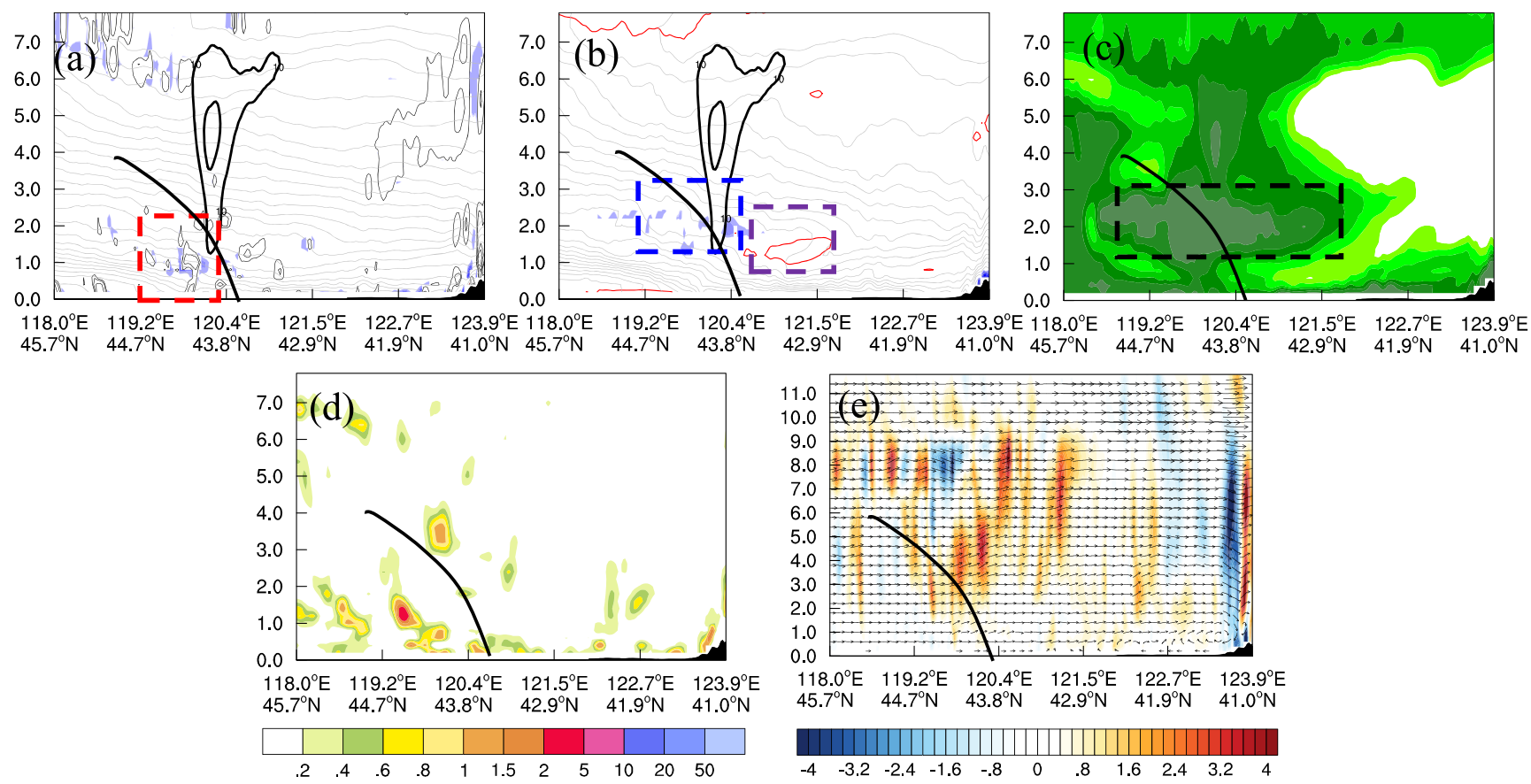

Fig. 11 Vertical cross-sections of the regions of (a) inertial instability (black line) and dry symmetrical instability (color shading), (b) CSI (color shading) and conditional instability (red solid line), (c) the relative humidity (units: \%), (d) frontogenesis (shading) and (e) vertical velocity (shading; units: $10^{-1} \mathrm{~m} \mathrm{~s}^{-1}$ ) along the line in Fig. 6d at 2230 UTC on 25 January 2017 in the Flat_upsm experiment. The thick solid contours are the 10 and $20 \mathrm{dBZ}$ simulated radar reflectivity. The gray contours in

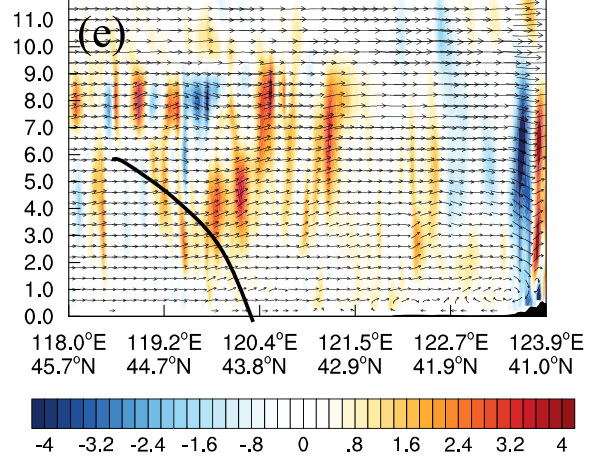

part (a) are the potential temperatures and the gray contours in part (b) are the saturated equivalent potential temperatures. The thick black lines indicate the leading edge of the front. The red, blue and purple dashed boxes indicate regions of inertial instability, the low-level CSI regions and the low-level conditional instability regions, respectively, which may contribute to the development of the snowband. The black dashed boxes indicate a low-level near-saturated layer 
and are responsible for the wide ascent region in the midtroposphere (3-7 km height, thick curved arrows) over the cold front. This provides a major lifting mechanism for the instabilities. Small-scale gravity waves appear at heights of 7.5-9.5 km and are produced by the ULJ (Fig. 9f). With the eastward propagation of small-scale upper gravity waves, the gravity wave ascents are able to integrate with the frontal ascents, forming strong ascending centers at mid-levels. This process is similar to the phase-locking of two different waves in wave dynamics and intensifies the frontogenetic lifting of the instabilities.

Based on the relative distributions of the ascent centers and the instabilities in Fig. 9d and e, weak reflectivities are formed at 2000 UTC in the Flat upsm experiment as a result of the release of the mid-layer conditional instability by the phaselocked lifting of the frontogenetic ascent and upper gravity wave ascent. Other instabilities in the lower levels (Fig. 9e), including conditional instability, CSI and inertial instability, have not yet played a part in inducing weak reflectivities. However, when the mid-level conditional instability is released, they will contribute to the subsequent development of the snowband.

This lifting mechanism is similar in the CTL experiment, with the main difference resulting from deep mountain gravity waves. As shown in Fig. 9a, deep gravity waves are produced by the flow passing over the terrain and are mixed with the upper gravity waves. This blocks the eastward propagation of the upper waves, inhibiting their integration with the frontogenetic ascents. The upper gravity waves due to the ULJ in the CTL experiments are therefore absent as lifting occurs. The release of mid-level conditional instability due
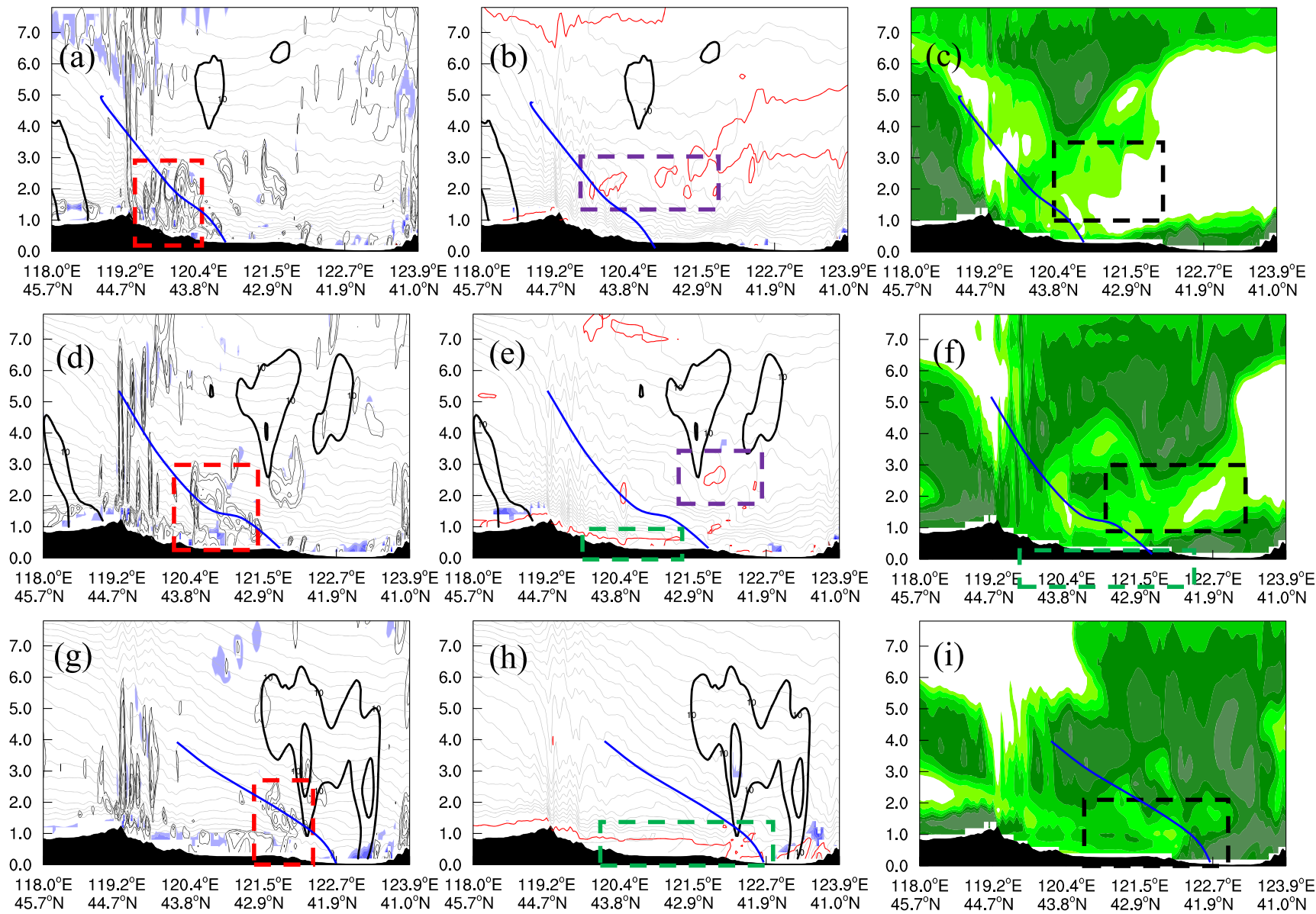

Fig. 12 Vertical cross-sections of the regions of $(\mathbf{a}, \mathbf{d}, \mathbf{g})$ inertial instability (black line) and dry symmetrical instability (color shading), (b, e, h) CSI (color shading) and conditional instability (red solid line) and $(\mathbf{c}, \mathbf{f}, \mathbf{i})$ the relative humidity (units: \%) along the line in Fig. 5d at 2230 UTC on 25 January 2017 (upper panels), 0100 UTC on 26 January 2017 (middle panels) and 0300 UTC on 26 January 2017 (lower panels) in the CTL experiment. The thick solid contours are the 10 and $20 \mathrm{dBZ}$ simulated radar reflectivities. The gray contours in parts (a), (d) and (g) are the potential temperatures and gray contours in parts (b), (e) and (h) are the saturated equivalent potential temperatures. The thick blue lines indicate the leading edge of the front. The red, purple and green dashed boxes indicate the regions of inertial instability, low-level conditional instability and near-surface conditional instability, respectively, which may contribute to the development of the snowband. The black dashed boxes indicate a low-level near-saturated layer 
to frontogenetic lifting contributes to the weak reflectivities in the CTL experiment.

We investigated how these general instabilities and possible lifting mechanisms cooperate to produce the weak bands based on their horizontal distributions. Figure 10 shows the horizontal distributions of the mid-layer conditional instability at the $\eta=0.50$ model height at 2000 UTC on 25 January 2017 in both experiments. Corresponding to the mid-level region of conditional instability and frontogenesis in the vertical sections, both the CTL and Flat_upsm experiments show a banded conditional instability region at $\eta=0.50$ model height (about $5 \mathrm{~km}$ ) and banded frontogenesis in the near-surface layer, which verifies the mechanism shown by the vertical cross-sections.

The similar mechanism for the weak bands - that is, the release of mid-level conditional instability by frontogenetic lifting, together with upper gravity waves-explains why the snowband in the CTL and Flat_upsm experiments has a similar process of development before 2000 UTC on 25 January 2017. However, we can still find two clear differences between the two experiments. One is the moist layer at a height of $1.0-3.0 \mathrm{~km}$ in the Flat_upsm experiment, which is absent in the CTL experiment (enclosed by blue dashed boxes, Fig. 7c and f). This layer changes the supply of water for the development of the snowband and it makes the atmosphere, which is unsaturated in the CTL experiment, near-saturated, resulting in the presence of CSI (Fig. 7e). The other difference is the mountain gravity waves (Fig. 9a), which may influence the lifting mechanism via deep vertical motions. These two factors play significant parts in the different processes of formation of snowbands in the CTL and Flat_upsm experiments.

\subsection{Band Formation after 2000 UTC on 25 January 2017 in the CTL and Flat_upsm Experiments}

Because the snowband forms earlier in the Flat_upsm experiment, Fig. 11 shows the vertical distributions of the relative humidity and instabilities in the Flat_upsm experiment at 2230 UTC on 25 January 2017 to illustrate the process of formation of the snowband. By comparing the humidity and instabilities at 2000 UTC in Fig. 7d-f with those at 2230 UTC in Fig. 11a-c, we find clear decreases in the inertial instability (black contours in the red dashed boxes), CSI (blue shading in the blue boxes) and conditional instability (red contours in the purple boxes) at lower levels near the cold front. This indicates that the lower level instabilities that had not taken effect on the weak reflectivities before 2000 UTC are now released to contribute to the formation of the snowband in the Flat_upsm experiment. The lifting responsible for releasing these instabilities also results from the integrated ascent of frontogenetic lifting and upper level gravity waves, which move to lower levels just over the cold frontal zone between 1.5 and $2.0 \mathrm{~km}$ (Fig. 11d and e).

For comparison, Figs. 12 and 13 present the related instabilities and lifting in the CTL experiment during the process of formation of the snowband. Here, as in the Flat_upsm experiment, we compare Fig. $7 \mathrm{a}-\mathrm{c}$ at 2000 UTC with Fig. $12 \mathrm{a}-\mathrm{c}$ at 2230 UTC. In Fig. 12a-c, the mid-level conditional instability that appears at 2000 UTC in Fig. $7 \mathrm{~b}$ also disappears in the CTL experiment. However, the low-level instabilities, especially the inertial instabilities, do not show a reduction compared with Fig. $7 \mathrm{a}$ and b. This explains why the snowband is not formed between 2000 and 2230 UTC in the CTL experiment.

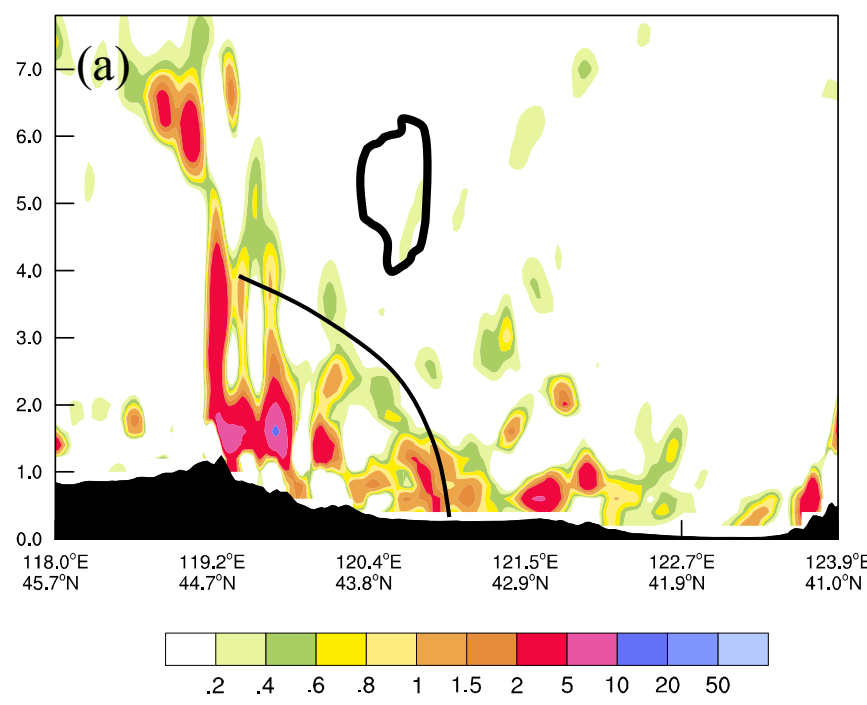

Fig. 13 Vertical cross-sections of the (a) frontogenesis (shading) and (b) vertical velocity (shading; units: $10^{-1} \mathrm{~m} \mathrm{~s}^{-1}$ ) along the line in Fig. $5 \mathrm{~d}$ at 2230 UTC on 25 January 2017 in the CTL experiment. The thick solid

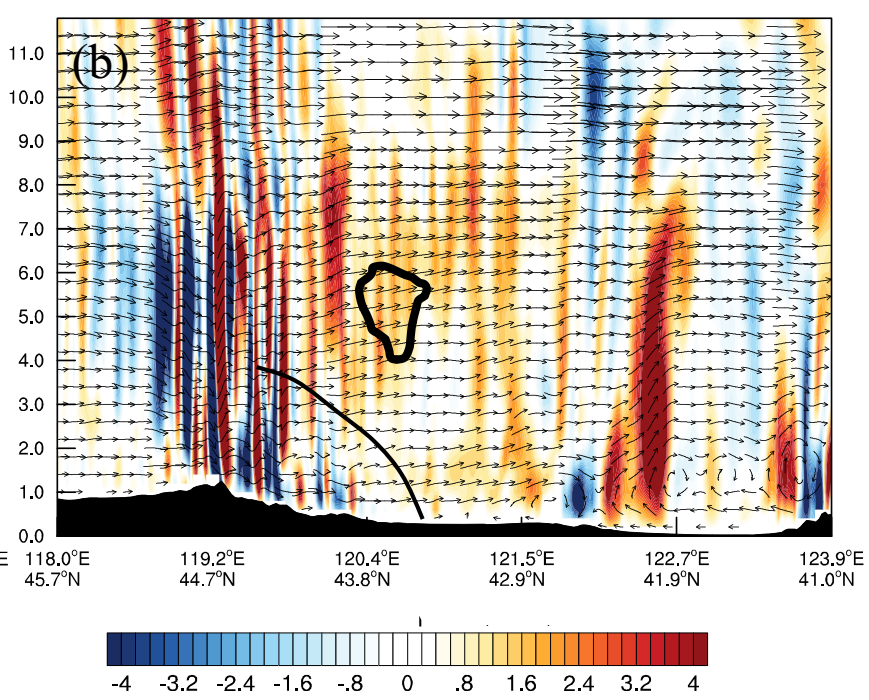

contours are the 10 and $20 \mathrm{dBZ}$ simulated radar reflectivities. The thick black lines indicate the leading edge of the front 
Two factors possibly contribute to the delay in the release of the low-level instabilities. One factor results from the lifting illustrated in Fig. 13a and b and Fig. 9a and b. At 2000 UTC (Fig. 9a and b), the inertial instabilities and conditional instabilities are mostly distributed over the topography; however, the frontogenetic ascent is disturbed by mountain gravity waves. Deep positive and negative vertical motion alternate rapidly, inhibiting the persistent lifting required to release the instabilities. With the eastward movement of the cold front and the surface cyclone, the regions of inertial and conditional
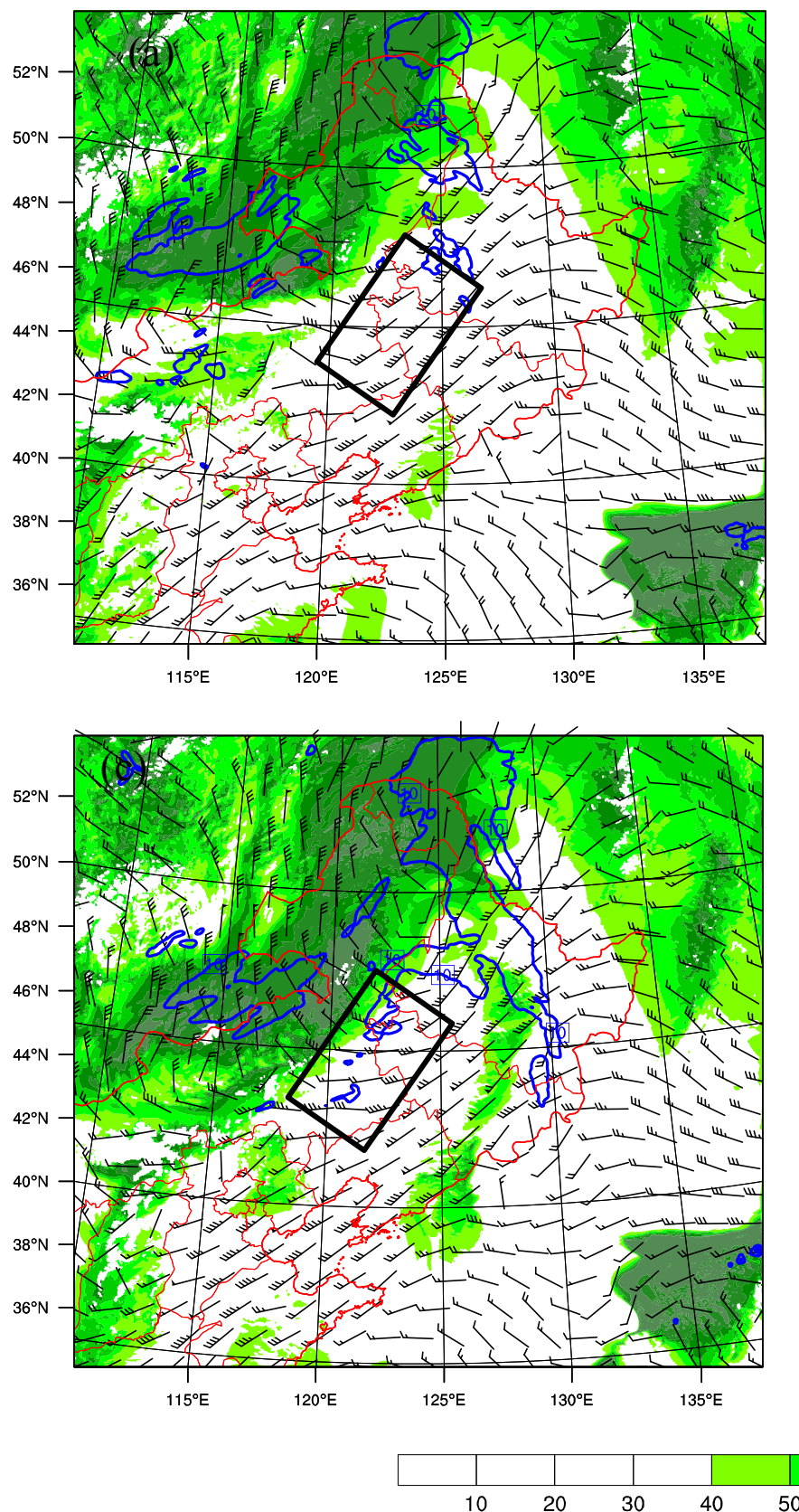

Fig. 14 Relative humidity at (a, b) 1600 UTC and (c, d) 2000 UTC on 25 January 2017 at $850 \mathrm{hPa}$ in the CTL experiment (left-hand column) and the Flat upsm experiment (right-hand column). The wind bars are the horizontal wind at $850 \mathrm{hPa}$. The blue contours are the 10 and $20 \mathrm{dBz}$ instability move out of the areas of the mountain gravity wave at 2230 UTC (Fig. 12b) and the instabilities are released, triggering convection under frontogenetic lifting (Fig. 13a and b). As in Fig. 12, apparent decreases in the lower level inertial and conditional instabilities can be observed with the development of the snowband after 2230 UTC (Fig. 12d and e and Fig. 12g and $h$, respectively).

The other factor contributing to the delay in the release of low-level instabilities is moisture, which is reflected in the vertical structure of the relative humidity in Figs. 11 and 12.
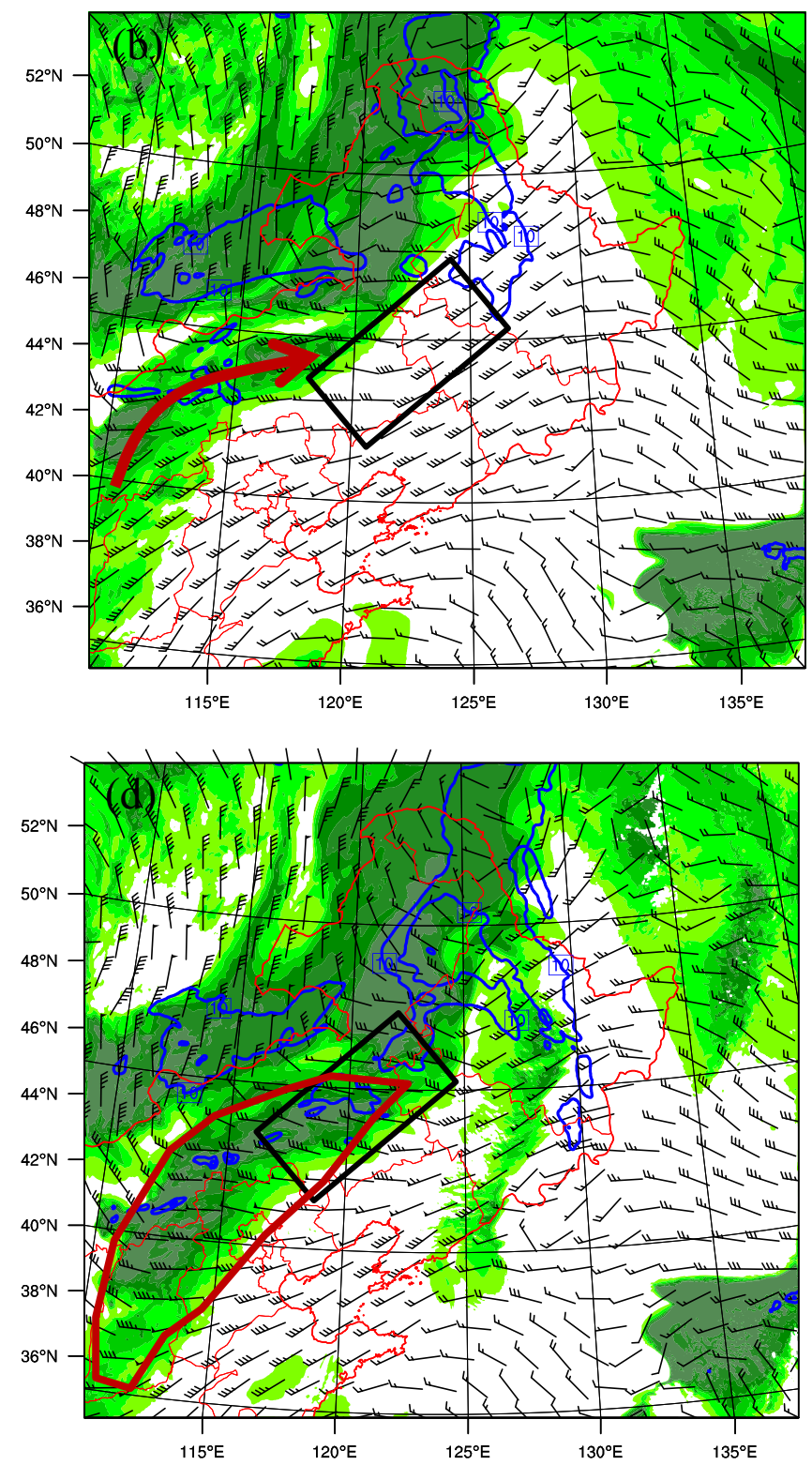

$\begin{array}{lllll}50 & 60 & 70 & 80 & 90\end{array}$

composite radar reflectivities. The black boxes indicate the region in which the snowband formed. The red curved arrow indicates a southwesterly flow for the supply of moisture and the red polygon encloses a moist belt in the Flat upsm experiment 
Figure 14 shows the horizontal distribution of the relative humidity at 1600 and 2000 UTC in the two experiments and it is clear that there is a difference in the supply of moisture in the CTL and Flat_upsm experiments. At 2000 UTC (Fig. 14c), the low-level atmosphere within the snowband on the leeward side of the mountain was relatively dry in the CTL experiment (black dashed box). A moist belt with a relative humidity up to $90 \%$ appears in the same location in the Flat_upsm experiment (enclosed by the red polygon in Fig. 14d), which results in a larger potential for precipitation.
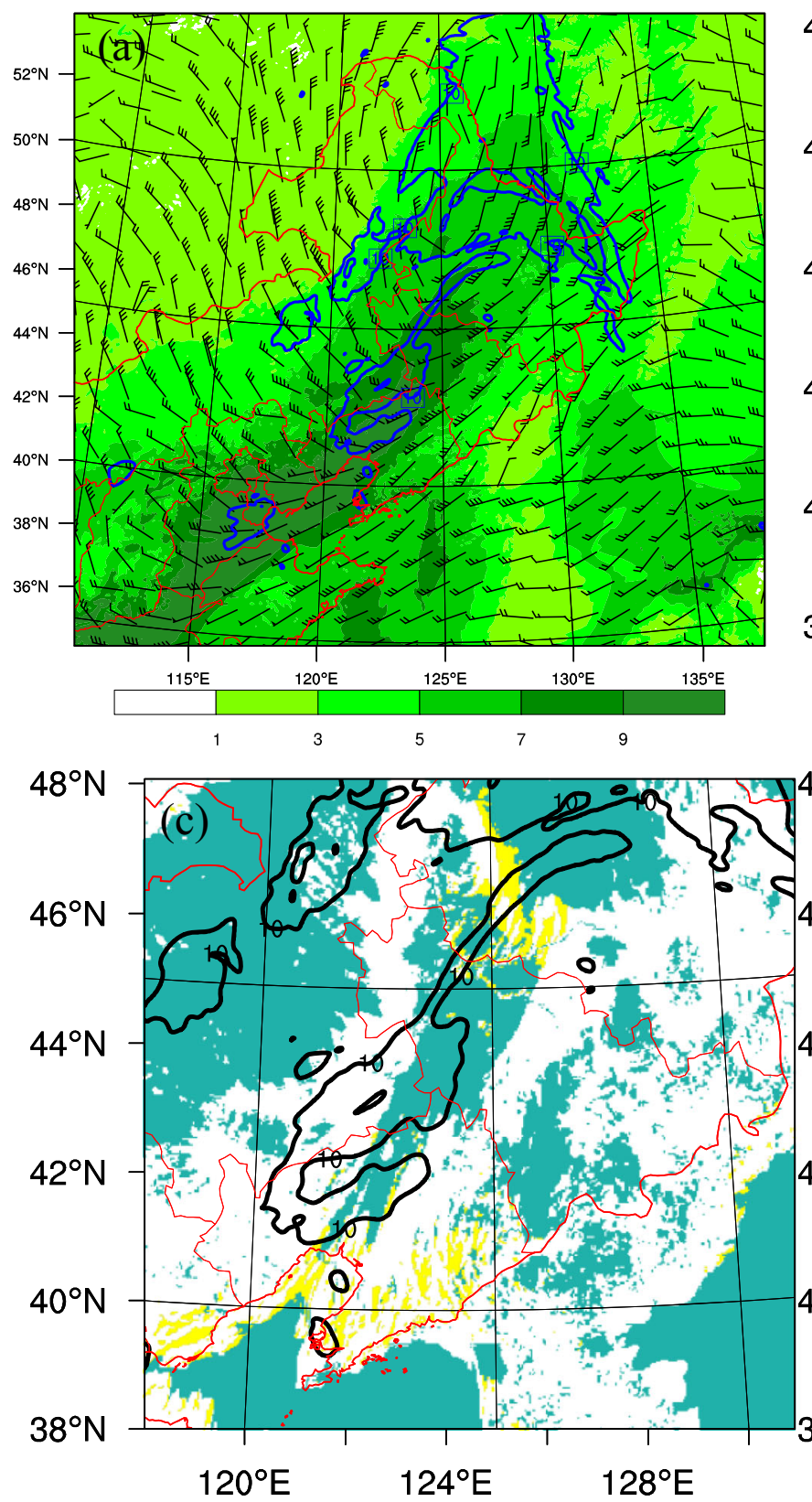

Fig. 15 Regions of (a) precipitable water (color shading), (b) frontogenesis (color shading), (c) conditional instability (green shading) and CSI (yellow shading) at a model level of $\eta=0.99$, (d) inertial instability (contours) and dry symmetrical instability (gray shading) at
The decrease in relative humidity leeward of the mountains is a common phenomenon resulting from downslope adiabatic heating. However, by tracing the moist belt in the Flat upsm experiment (Fig. 14d), we found that this belt extends from a moist southwesterly LLJ that appears at about 1600 UTC and then moves eastward to influence the development of the snowband (Fig. 14b, red curved arrow). This moist flow in the CTL experiment is largely reduced due to the deflection of the upstream terrain (Fig. 14a), decreasing the supply of moisture for the formation of the snowband.
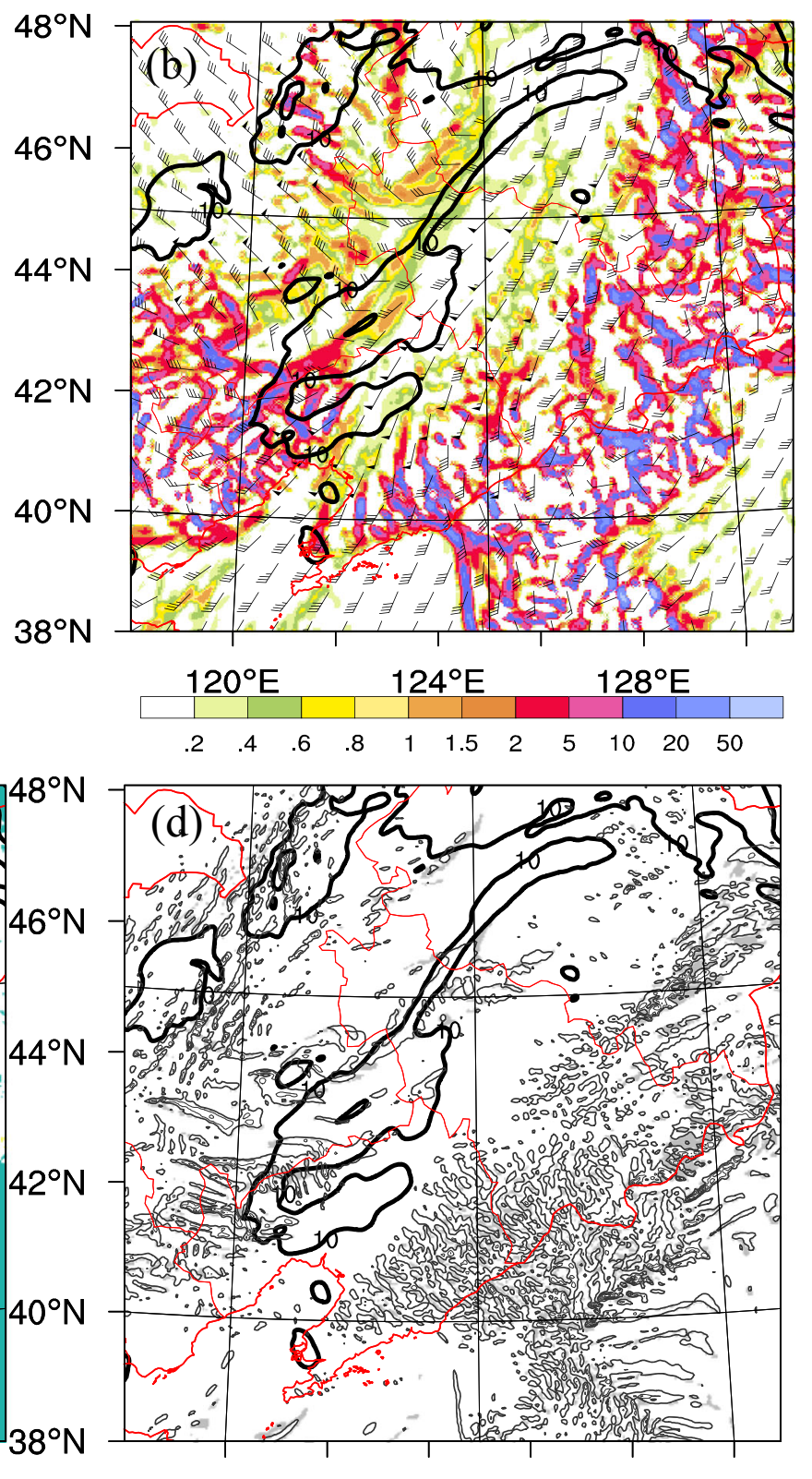

\section{$120^{\circ} \mathrm{E} \quad 124^{\circ} \mathrm{E} \quad 128^{\circ} \mathrm{E}$}

the $\eta=0.84$ model height in the CTL experiment at 0100 UTC on 26 January 2017. The blue contours in part (a) and black contours in part (bd) are the 10 and $20 \mathrm{dBZ}$ radar reflectivity. The wind bars are the horizontal wind at $850 \mathrm{hPa}$ 

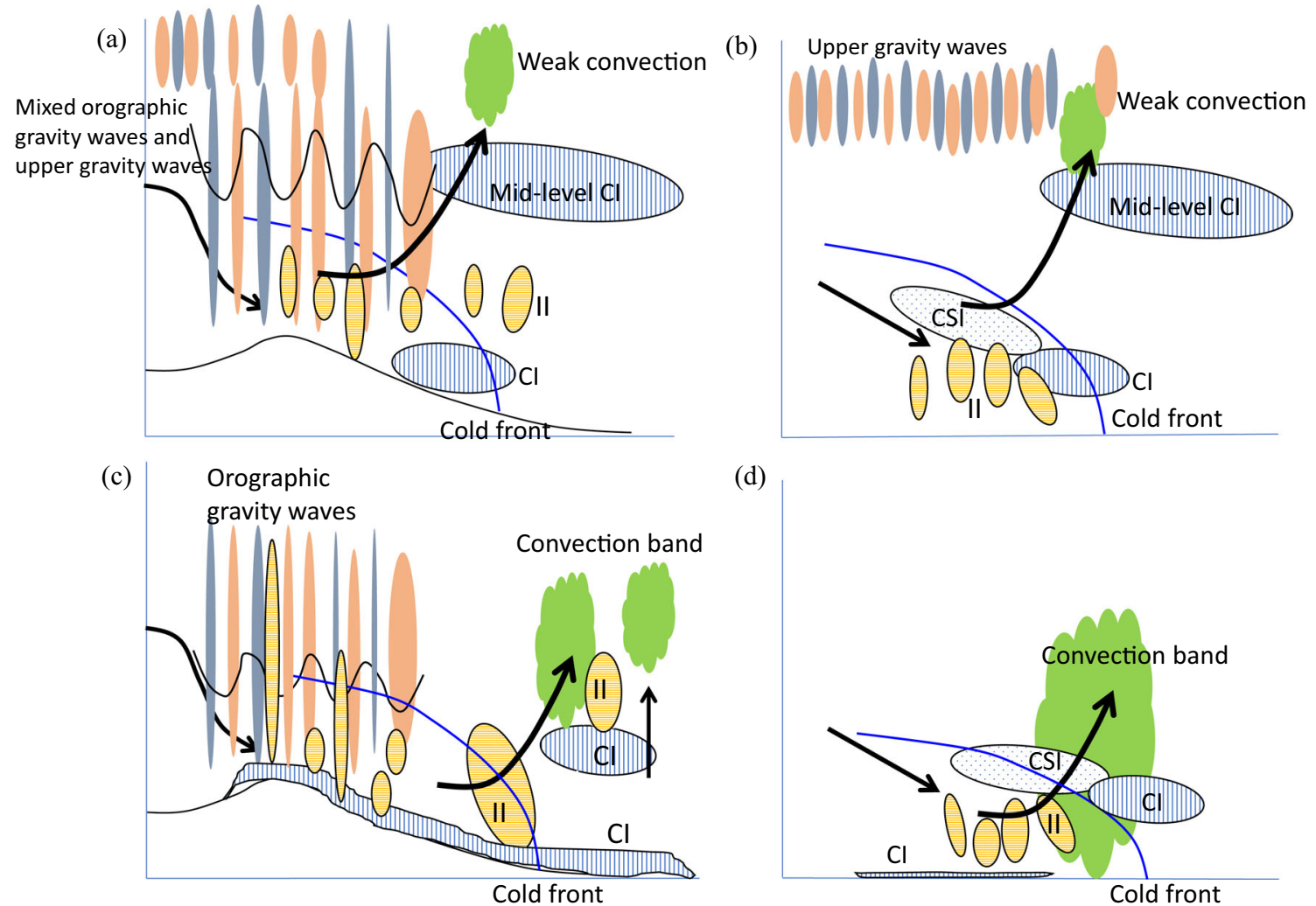

(d)

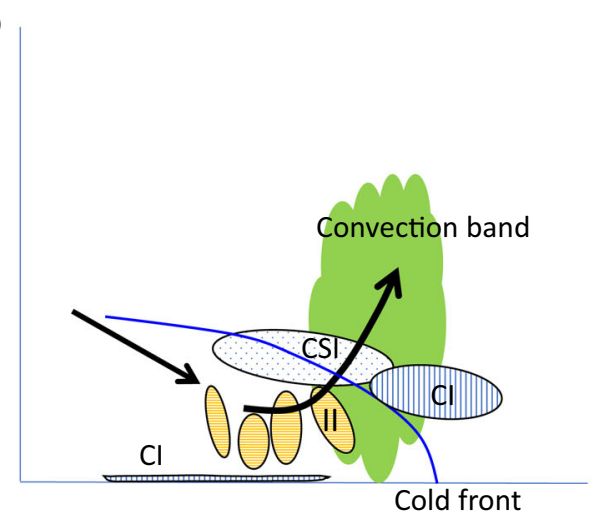

Fig. 16 Conceptual models of snowband formation for snow bursts with and without the influence of the upstream terrain: (a-b) weak band period; (c-d) band formation period. CI, conditional instability; CSI, conditional symmetrical instability; and II, inertial instability

Figure 12 shows that, in addition to the release of low-level instabilities by frontogenetic ascent, a near-surface conditional instability layer appears in the CTL experiment. This layer promotes the formation of a snowband in a strong frontogenesis environment (Fig. 13a). This layer is associated with the cold air behind the cold front and provides major instabilities for the subsequent development of the snowband, which is beyond the scope of the current study.

These analyses examined the development of radar reflectivities during band formation in the vertical direction. Figure 15 shows how these reflectivities formed a banded structure in the horizontal direction. Corresponding to the three ingredients (moisture, instability and lift), three factors may contribute to the band structure: (1) a banded supply of moisture (Fig. 14e and f); (2) banded frontogenesis; and (3) banded conditional instability (or CSI). Figure 15a shows that the snowband in the CTL experiment formed in the highprecipitation water bands. Figure $15 \mathrm{~b}$ shows that the nearsurface frontogenesis has a clear banded structure along the banded reflectivities. Instabilities that may contribute to this band structure include the near-surface conditional instability or CSI (Fig. 15c). Inertial instabilities do not seem to contribute to the band structure as a result of their scattered distributions in the snowband (Fig. 15d). It is likely that they influence the distributions of snowfall embedded in the snowband, but not the structure of the band.

\section{Conclusions}

A snowband formed along an eastward-moving cold front on 26-27 January 2017 and produced heavy snow in Northeast China under the influence of the local terrain. The northeastsouthwest-oriented snowband developed leeward of the Greater Khingan Mountains, moved eastward with the cold front and then encountered the Changbai mountain range, where heavy snow was produced.

The process for the formation of the snowband was reproduced by the WRF model to provide high-resolution data for analyses (the CTL experiment). In addition, several sensitivity experiments that gradually removed the upstream terrain were conducted to reveal the role of the upstream terrain on the formation of the snowband. A comparison of the snowfall and band development process in the CTL and sensitivity experiments show the apparent negative effects of the upstream topography on the formation of the snowband, especially the large-scale terrain. From the point of view of the three ingredients necessary for precipitation (moisture, instability and lift), we studied the mechanism of formation of the snowband along the cold front in the CTL experiment and the Flat upsm experiment (which removes all the upstream terrain) to determine the negative effects of the upstream terrain.

Figure 16 shows the conceptual model for the band formation processes in the two experiments. The conceptual model 
separates the process of formation of the snowband into two periods (the weak band period and the band formation process) based on their different mechanisms. In the weak band period, the release of the mid-level conditional instability lifted by frontogenetic ascent, with or without upper gravity waves, contributes to the development of weak bands in both the experiments with and without terrain. The lower level instabilities are not released during this period and the weak bands in the two experiments do not exhibit many differences.

In the band formation process, the low-level or near-surface instabilities are released by frontogenetic lifting, resulting in the formation of the band in both experiments. However, the band forms nearly four hours later in the CTL experiment than in the Flat_upsm experiment and is also much weaker. Two main factors contribute to this difference.

This first factor is the result of the mountain gravity waves produced by the upstream topography. These waves perturb the frontal circulation over the mountain and change the persistent lifting required for the release of low-level instabilities. The release of these instabilities therefore occurs much later in the CTL experiment than in the Flat_upsm experiment.

The second factor is the upstream terrain, which changes the transport of moisture in the CTL experiment as a result of blocking effects. This leads to a relatively dry environment in the region of band formation, which does not favor precipitation. The low-level instability structures are also changed-for example, the CSI has an apparent banded structure in the Flat_upsm experiment, but not in the CTL experiment.

Acknowledgments We thank the two anonymous reviewers and the editor for their valuable comments and suggestions.

Funding This study was supported by the National Key Research and Development Project (2018YFC1507104), Strategic Pilot Science and Technology Special Program of the Chinese Academy of Sciences (XDA17010105), the Key Scientific and Technology Research and Development Program of Jilin Province (20180201035SF), the National Natural Science Foundation of China (41875056, 41775140, 42075013 and 41575065) and the Science and Technology Innovation Development Project of China Meteorological Administration (SSCX201905).

Open Access This article is licensed under a Creative Commons Attribution 4.0 International License, which permits use, sharing, adaptation, distribution and reproduction in any medium or format, as long as you give appropriate credit to the original author(s) and the source, provide a link to the Creative Commons licence, and indicate if changes were made. The images or other third party material in this article are included in the article's Creative Commons licence, unless indicated otherwise in a credit line to the material. If material is not included in the article's Creative Commons licence and your intended use is not permitted by statutory regulation or exceeds the permitted use, you will need to obtain permission directly from the copyright holder. To view a copy of this licence, visit http://creativecommons.org/licenses/by/4.0/.

\section{References}

Abulikemu, A., Wang, Y., Gao, R., et al.: A Numerical Study of Convection Initiation Associated With a Gust Front in Bohai Bay Region, North China. J. Geophys. Res. 124, 13843-13860 (2019)

Barrett, A.I., Gray, S.L., Kirshbaum, D.J., Roberts, N.M., Schultz, D.M., Fairman, J.G.: Synoptic versus orographic control on stationary convective banding. Quart. J. Roy. Meteor. Soc. 141, 1101-1113 (2015)

Bennetts, D.A., Hoskins, B.J.: Conditional symmetric instability-a possible explanation for frontal rainbands. Quart. J. Roy. Meteor. Soc. 105, 945-962 (1979)

Burnett, A.W., Kirby, M.E., Mullins, H.T., Patterson, W.P.: Increasing great Lake-effect snowfall during the twentieth century: a regional response to global warming? J. Clim. 16, 3535-3542 (2003)

Clark, J.H.E., James, R., Grumm, R.H.: A reexamination of the mechanisms responsible for banded precipitation. Mon. Wea. Rev. 130, 3074-3086 (2002)

Cosma, S., Richard, E., Miniscloux, F.: The role of small-scale orographic features in the spatial distribution of precipitation. Quart. J. Roy. Meteor. Soc. 128, 75-92 (2002)

Dong, X., Zhou, X.W., Hu, Z.M., et al.: Characteristics of spatial and temporal variation of heavy snowfall in Northeast China in recent 50 years. Meteorological Monthly. 12, 74-79 (2010)

Doswell, C.A., Brooks III, H.E., Maddox, R.A.: Flash flood forecasting: an ingredients-based methodology. Wea. Forecasting. 11, 560-581 (1996)

Gohm, A., Mayr, G.: Numerical and observational case study of a deep Adriatic bora. Quart. J. Roy. Meteor. Soc. 131, 1363-1392 (2005)

Jiang, Q., Smith, R.B., Doyle, J.: The nature of the mistral: observations and modelling of two MAP events. Quart. J. Roy. Meteor. Soc. 129, $857-875$ (2003)

Li, N., Jiao, B.F., Ran, L.K., et al.: Influence of Upstream Terrain on the Initial Development of a Cold-Frontal Snowband in Northeast China. Adv. Atmos. Res, Accepted (2021)

Kawashima, M.: The role of vertically propagating gravity waves forced by melting-induced cooling in the formation and evolution of wide cold-frontal rainbands. J. Atmos. Sci. 73, 2083-2836 (2016)

Kirshbaum, D.J., Durran, D.R.: Observations and modeling of banded orographic convection. J. Atmos. Sci. 62, 1463-1479 (2005)

Kirshbaum, D.J., Schultz, D.M.: Convective cloud bands downwind of mesoscale mountain ridges. J. Atmos.Sci. 75, 4265-4286 (2018)

Klemp, J.B., Dudhia, J., Hassiotics, A.D.: An upper gravity-wave absorbing layer for NWP applications. Mon. Wea. Rev. 136, 3987-4006 (2008)

Milrad, S.M., Gyakum, J.R., Atallah, E.H., Smith, J.F.: A diagnostic examination of the eastern Ontario and western Quebec wintertime convection of 28 January 2010. Wea. Forecasting. 26, 301-318 (2011)

Milrad, S.M.: Gyakum, Lombardo, K., Atallah, E. H.: on the dynamics, thermodynamics, and forecast model evaluation of two snow-burst events in southern Alberta. Wea. Forecasting. 29, 725-749 (2014)

Niziol, T.A., Snyder, W.R., Waldstreicher, J.S.: Winter weather forecasting throughout the eastern United-States. 4. Lake-effect snow. Wea. Forecasting. 10, 61-77 (1995)

Novak, D.R., Bosart, L.F., Keyser, D., Waldstreicher, J.S.: An observational study of cold season banded precipitation in northeast U.S. cyclones. Wea. Forecasting. 19, 993-1010 (2004)

Novak, D.R., Waldstreicher, J.S., Keyser, D., Bosart, L.F.: A forecast strategy for anticipating cold season mesoscale band formation within eastern U.S. cyclones. Wea. Forecasting. 21, 3-23 (2006)

Novak, D.R., Colle, B.A., Yuter, S.E.: High-resolution observations and model simulations of the life cycle of an intense mesoscale snowband over the northeastern United States. Mon. Wea. Rev. 136, 1433-1456 (2008) 
Novak, D.R., Colle, B.A., McTaggart-Cowan, R.: The role of moist processes in the formation and evolution of mesoscale snowbands within the comma head of northeast U.S. cyclones. Mon. Wea. Rev. 137, 2662-2686 (2009)

Novak, D.R., Colle, B.A., Aiyyer, A.R.: Evolution of mesoscale precipitation band environments within the comma head of northeast U.S. cyclones. Mon. Wea. Rev. 138, 2354-2374 (2010)

Pettegrew, B.P., Market, P.S., Wolf, R.A., Holle, R.L., Demetriades, N.W.S.: A case study of severe winter convection in the Midwest. Wea. Forecasting. 24, 121-139 (2009)

Rotunno, R., Ferretti, R.: Orographic effects on rainfall in MAP cases IOP 2b and IOP 8. Quart. J. Roy. Meteor. Soc. 129, 373-390 (2003)

Schär, C., Sprenger, M., Lüthi, D., Jiang, Q., Smith, R.B., Benoit, R.: Structure and dynamics of an Alpine potential-vorticity banner. Quart. J. Roy. Meteor. Soc. 129, 825-855 (2003)

Schultz, D.M., Schumacher, P.N.: The use and misuse of conditional symmetric instability. Mon. Wea. Rev. 127, 2709-2732 (1999)

Schultz, D.M., Knox, J.A.: Banded convection caused by frontogenesis in a conditionally, symmetrically, and Inertially unstable environment. Mon. Wea.Rev. 135, 2095-2110 (2007)

Schumacher, R.S., Schultz, D.M., Knox, J.A.: Convective Snowbands downstream of the Rocky Mountains in an environment with conditional, dry symmetric, and inertial instabilities. Mon. Wea.Rev. 138, 4416-4438 (2010)
Schumacher, R.S., Schultz, D.M., Knox, J.A.: Influence of terrain resolutionon banded convection in the lee of the Rocky Mountains. Mon. Wea. Rev. 143, 1399-1416 (2015)

Sidersleben, S.K., Gohm, A.: The missing link between terrain-induced potential Vorticity banners and banded convection. Mon. Wea. Rev. 144, 4063-4080 (2016)

Sun, B., Wang, H.J.: Water vapor transport paths and accumulation during widespread snowfall events in northeastern China. J. Clim. 26, 4550-4566 (2013)

Sun, J.Q., Wang, H.J., Yuan, W.: A preliminary investigation on causes of the catastrophic snowstorm in march, 2007 in northeastern part of China. J. meteor. Res. 67, 469-477 (2009)

Wang, H.J., Yu, E., Yang, S.: An exceptionally heavy snowfall in Northeast China: large-scale circulation anomalies and hindcast of the NCAR WRF model. Meteorog. Atmos. Phys. 113, 11-25 (2011a)

Wang, J., Zuo, L., Zhao, C., Luo, D.: Inhomogeneity characteristics of snow in Northeast China. J. Geogr. Sci. 21, 621-633 (2011b)

Weckwerth, T.M., Parsons, D.B.: A review of convection initiation and motivation for IHOP 2002. Mon. Wea. Rev. 134, 5-22 (2016)

Publisher's Note Springer Nature remains neutral with regard to jurisdictional claims in published maps and institutional affiliations. 